\title{
High-throughput reaction engineering to assess the oxidation stability of MAX phases
}

\author{
D. Sauceda ${ }^{1,4}$, P. Singh ${ }^{1,3,4 凶}$, A. R. Falkowski ${ }^{1}$, Y. Chen ${ }^{1}$, T. Doung ${ }^{1}$, G. Vazquez ${ }^{1}$, M. Radovic ${ }^{1}$ and R. Arroyave $\mathbb{D}^{1,2 凶}$
}

The resistance to oxidizing environments exhibited by some $M_{n+1} A X_{n}$ (MAX) phases stems from the formation of stable and protective oxide layers at high operating temperatures. The MAX phases are hexagonally arranged layered nitrides or carbides with general formula $M_{n+1} A X_{n}, n=1,2,3$, where $M$ is early transition elements, $A$ is $A$ block elements, and $X$ is $C / N$. Previous attempts to model and assess oxide phase stability in these systems has been limited in scope due to higher computational costs. To address the issue, we developed a machine-learning driven high-throughput framework for the fast assessment of phase stability and oxygen reactivity of 211 chemistry MAX phase $M_{2} A X$. The proposed scheme combines a sure independence screening sparsifying operator-based machine-learning model in combination with grand-canonical linear programming to assess temperaturedependent Gibbs free energies, reaction products, and elemental chemical activity during the oxidation of MAX phases. The thermodynamic stability, and chemical activity of constituent elements of $\mathrm{Ti}_{2} \mathrm{AIC}$ with respect to oxygen were fully assessed to understand the high-temperature oxidation behavior. The predictions are in good agreement with oxidation experiments performed on $\mathrm{Ti}_{2} \mathrm{AIC}$. We were also able to explain the metastability of $\mathrm{Ti}_{2} \mathrm{SiC}$, which could not be synthesized experimentally due to higher stability of competing phases. For generality of the proposed approach, we discuss the oxidation mechanism of $\mathrm{Cr}_{2} \mathrm{AlC}$. $\mathrm{The}$ insights of oxidation behavior will enable more efficient design and accelerated discovery of MAX phases with maintained performance in oxidizing environments at high temperatures.

npj Computational Materials (2021)7:6; https://doi.org/10.1038/s41524-020-00464-7

\section{INTRODUCTION}

$M_{n+1} A X_{n}$ (MAX) phases belong to the group of ternary carbides and nitrides in which $M$ is early transition metal, $A$ is group 13-16 element and $\mathrm{X}$ is $\mathrm{C}$ or $\mathrm{N}^{1-3}$. Unlike conventional ceramics, MAX phases are machinable ${ }^{4}$ and have unique combination of properties such as low density, high strength ${ }^{5}$, excellent thermal shock resistance, and damage tolerance ${ }^{6}$. MAX phases are particularly useful due to their high-temperature stability, making them suitable for structural applications-under extreme (or at least elevated) ambient temperature conditions-in a number of industries, including nuclear power and aerospace propulsion systems ${ }^{4}$. Tailoring the composition within the MAX crystal system can provide further control of the chemical, mechanical, magnetic, and thermal properties of these compounds ${ }^{2}$. Unfortunately, at elevated temperatures and under oxidizing conditions, most MAX phases undergo detrimental self-sustaining oxidation reactions that result in catastrophic loss of mechanical integrity ${ }^{4,7-9}$.

The oxidation behavior of ceramic materials such as MAX phases has often been used as a primary materials selection criterion for high-temperature applications. The potential oxidation resistance of a candidate MAX phase depends on its ability to form a stable passivating oxide layer as weakly bonded elements that typically reside in the A-sites react with oxygen in the environment. The $\mathrm{Al}, \mathrm{Cr}$, or Si-containing MAX phases have been shown to provide varying degrees of protection from further oxidation by forming primarily $\mathrm{Al}_{2} \mathrm{O}_{3}, \mathrm{Cr}_{2} \mathrm{O}_{3}$, or $\mathrm{SiO}_{2}$ protective coatings at high temperatures ${ }^{7,10} . \mathrm{Ti}_{2} \mathrm{AlC}_{1} \mathrm{Ti}_{3} \mathrm{AlC}_{2}, \mathrm{Cr}_{2} \mathrm{AlC}$, or $\mathrm{Ti}_{3} \mathrm{SiC}_{2}$ are few such examples of $\mathrm{Al}, \mathrm{Cr}$, or Si-containing MAX phases, where the weakly bonded A-element $(\mathrm{Al}, \mathrm{Si})$ is capable of leaving the layered lattice to form protective predominately $\mathrm{Al}_{2} \mathrm{O}_{3}$ and
$\mathrm{SiO}_{2}$ oxide scales during high-temperature oxidation ${ }^{7,8,11}$. The facile formation of a protective Al-/Si-based oxide layer is likely the result of a higher $\mathrm{Al} / \mathrm{Si}$ diffusivity and chemical activity when compared to $M$ element, that makes them readily available for oxidation at the surface of the MAX phase compound in contact with an oxidizing environment ${ }^{12-15}$.

Despite the fact that the assessment of oxidation behavior in MAX phases is of critical importance for their further development as a high-temperature structural or coating material, to date there is no current computational approach capable of quickly assessing the oxide phase stability of arbitrary MAX phase compositions. Such an approach could in turn be used to guide the experimental discovery and optimization of MAX phases with superior hightemperature performance under oxidizing conditions. Unfortunately, the oxidation process is very complex and expensive to model computationally, and to characterize experimentally. It requires detailed and definitive studies of oxide thickness, stresses, diffusion coefficients, equilibrium parameters, and volume change as functions of oxidation temperature and time ${ }^{16-18}$. On the computational front, assessment of the phase stability of a materials system under oxidation requires full knowledge of the finite-temperature thermodynamics of all phases likely to take part in equilibrium at particular conditions (temperature and composition of the system). This information may not be readily available in conventional thermodynamic databases and is exceedingly expensive to acquire from firstprinciples methods ${ }^{19}$.

To address the computational bottleneck, we present an automated machine-learning-based scheme to predict favorable thermodynamic reactions and oxidation behavior of MAX phases

\footnotetext{
${ }^{1}$ Department of Materials Science \& Engineering, Texas A\&M University, College Station, TX 77843, USA. ${ }^{2}$ Department of Mechanical Engineering, Texas A\&M University, College Station, TX 77843, USA. ${ }^{3}$ Present address: Ames Laboratory, US Department of Energy, lowa State University, Ames, IA 50011, USA. ${ }^{4}$ These authors contributed equally: D. Sauceda, P. Singh. ${ }^{凶}$ email: psingh84@ameslab.gov; raymundo.arroyave@tamu.edu
} 
at elevated temperatures at different oxygen partial pressures $\left(\mathrm{pO}_{2}\right)$. Our workflow combines sure independence screening and sparsifying operator (SISSO) $)^{20-22}$ with grand-canonical linear programming (GCLP) $)^{23,24}$ into a single framework to predict the phase stability of product phases of the general $\left[M_{n+1} A X_{n}+O_{2}\right]$ reaction at elevated temperatures. Here, we mainly focused on $n=1 \mathrm{MAX}$ phase, i.e., $\mathrm{M}_{2} \mathrm{AX}$, where early transition elements (M), group-13/14 $(A=A l, S i)$, and group-14 $(C, N)$ elements are mixed in 2:1:1 ratio. Experimental enthalpy and total energy database of transition metal oxides and other (binary, ternary) phases, required to predict finite-temperature Gibbs' free energies $\left(\Delta G_{\text {form }}\right)$ by SISSO, are taken from the NIST-JANAF thermochemical tables ${ }^{25,26}$, Open Quantum Materials Database (OQMD) ${ }^{27}$, and first-principles density functional calculations. GCLP uses temperature-dependent $\Delta G_{\text {form }}$ from SISSO to predict $\left[\mathrm{M}_{2} \mathrm{AX}+\mathrm{O}_{2}\right]$ reaction products, fractions of the product states, and their chemical activities for given temperature and oxygen content. Among the aluminaforming MAX phases, we choose $\mathrm{Ti}_{2} \mathrm{AlC}$ for detailed comparative theoretical and experimental study because of its practical applications ${ }^{28,29}$. Our high-throughput predictions compare well with experiments. We also present a detailed discussion on our predictions on oxidation behavior of $\mathrm{Cr}_{2} \mathrm{AlC}$ in order to show the generality of our scheme.

\section{RESULTS AND DISCUSSION}

Model evaluation

Since model evaluation is a very important criteria in machinelearning approaches, we use composition-dependent $\mathrm{Ti}_{x} \mathrm{O}_{1-x}$ (see Supplementary Fig. 1 for $\mathrm{Al}_{x} \mathrm{O}_{1-x}$ ) as a test set to validate the $\mathrm{SISSO}^{20-22}$ predictions by calculating temperature-dependent convex hull as shown in in Fig. 1a (see Supplementary Table 1). Our predictions and error in predictions of $\Delta G_{\text {form }}$ for $\mathrm{Ti}_{x} \mathrm{O}_{1-x}$ are validated against the experimental dataset from NIST-JANAF thermochemical tables ${ }^{25}$. Model predicts $\mathrm{TiO}_{2}, \mathrm{Ti}_{3} \mathrm{O}_{5}, \mathrm{TiO}_{3}, \mathrm{TiO}$, $\mathrm{Ti}_{2} \mathrm{O}, \mathrm{Ti}_{3} \mathrm{O}$, and $\mathrm{Ti}_{6} \mathrm{O}$ as seven stable phases at $300 \mathrm{~K}$, whereas $\mathrm{Ti}_{2} \mathrm{O}$ and $\mathrm{Ti}_{6} \mathrm{O}$ phases disappear from the convex hull at $1800 \mathrm{~K}$. The convex hull at any given temperature suggests thermodynamic stability of that phase or composition, whereas any phase above the convex hull is thermodynamically metastable. The error (RMSE) in the predictions of $\Delta G_{\text {form }}$ of $\mathrm{Ti}_{x} \mathrm{O}_{1-x}$ increases with temperature with outliers emerging at higher temperatures in Fig. $1 \mathrm{~b}-\mathrm{d}$, which possibly originates from the use of $0 \mathrm{~K}$ cell volumes of the involved phases as a feature used to compute the finitetemperature Gibbs free energy of formation. The increase in prediction error $\left(R^{2}\right)$ at elevated temperatures, in part, may also stem from possible phase changes at higher temperatures. Regardless of these limitations, the close agreement between predicted and experimental $\Delta G_{\text {form }}$ at higher temperatures in Fig. 1 indicates that the prediction error in $\Delta G_{\text {form }}$ can be minimized by proper assessment of formation enthalpies. The phases of Ti-O compounds that underwent gas phase transitions were omitted at higher temperatures ${ }^{21}$.

The SISSO framework predicts the $\Delta G_{\text {form }}$ using the $\Delta H_{\text {form }}$ as input as accessed from $\mathrm{OQMD}^{27}$, which is defined conventionally as the difference of total energies between a compound and its constituent elements as $\Delta H_{\text {form }}=E_{\text {total }}^{\text {compound }}-\sum_{\mathrm{i}} n_{\mathrm{i}} E_{\mathrm{i}}$, where $E_{\text {total }}^{\text {compound }}$ is the total energy of the alloy, $\left(n_{i}, E_{\mathrm{i}}\right)$ is the number of atoms and elemental energy of type " $i$ ". The SISSO predicted $\Delta G_{\text {form }}$ correspond to a single phase, not to the entire convex hull. A set of $\Delta G_{\text {form }}$ are used to compute the convex hull (as a function of temperature), see Fig. 1 (Ti-O) and Supplementary Fig. 2 (Al-O).

\section{SISSO predicted $\Delta G_{\text {form }}$ of MAX phases}

The $\Delta G_{\text {form }}$ is the relevant thermodynamic potential to assess thermodynamic equilibrium under isobaric/isothermal conditions for closed systems. Its minimization naturally leads to the
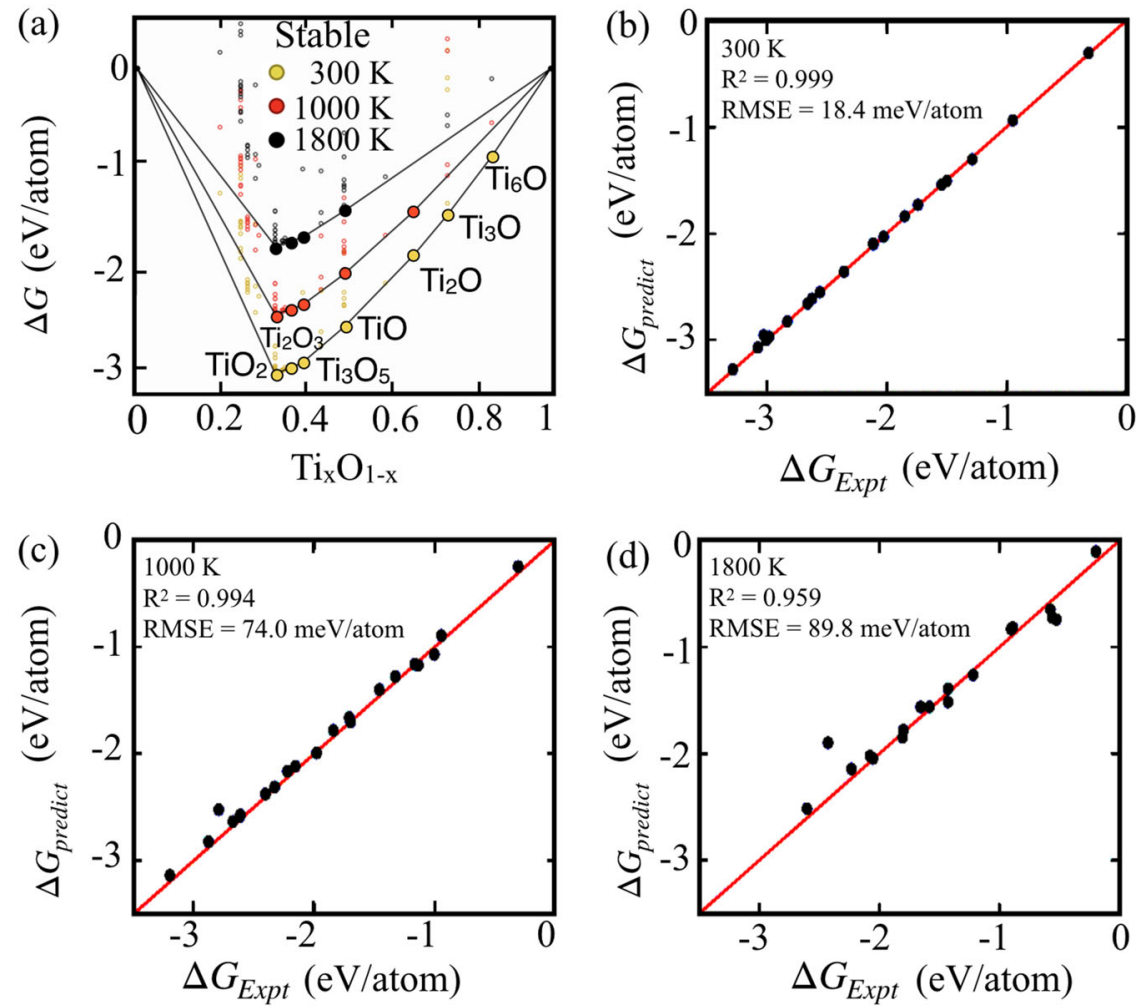

Fig. 1 Validation of Ti-O phase stability. a Convex hull of $\mathrm{Ti}_{1-x} \mathrm{O}_{x}$ generated using SISSO model, and (b-d) corresponding error in prediction compared to experimental (NIST-JANAF) dataset at 300,1000, and $1800 \mathrm{~K}$. The error in prediction increases with temperature due to use of $0 \mathrm{~K}$ unit cell volumes. 

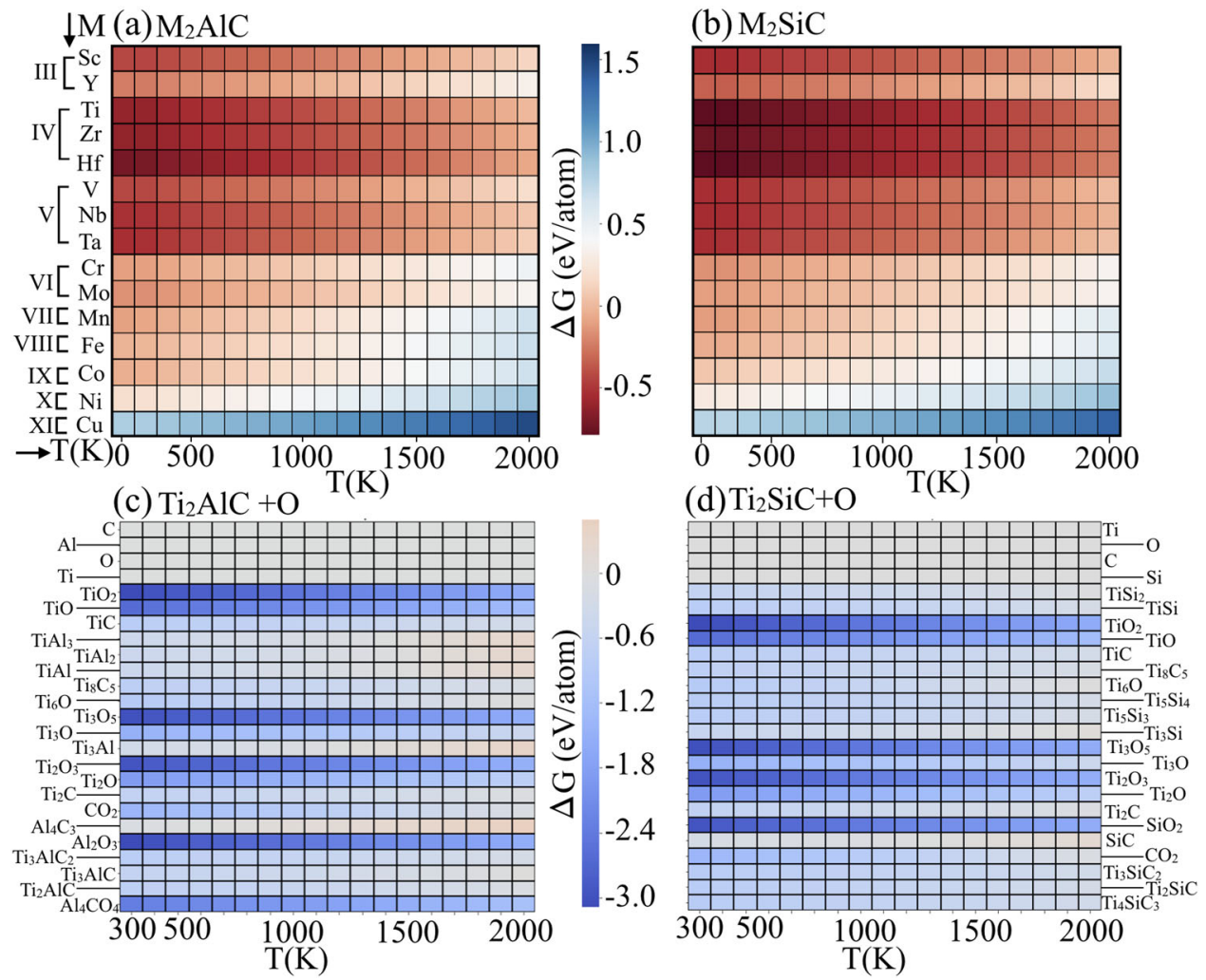

Fig. 2 Gibbs formation enthalpy prediction of MAX phases. Stability heat map for $\mathbf{a} \mathrm{M}_{2} \mathrm{AIC}$, and $\mathbf{b} \mathrm{M}_{2} \mathrm{SiC}$ MAX phases. M elements organized by periodic group, arranged by increasing valence electron count. Also see SISSO predicted $\Delta G_{\text {form }}$ in Table S3 of other binary and ternary phases. c-d Heat map of competing phase for $\mathrm{Ti}_{2} \mathrm{AIC}$ and $\mathrm{Ti}_{2} \mathrm{SiC}$ MAX phases during oxidation process in presence of static oxygen $\left(\mathrm{O}_{2}\right)$ at temperatures $300-2000 \mathrm{~K}$.

determination of the most stable equilibrium state and can thus be used to assess the resulting reaction products for a given set of reactants. Therefore, the knowledge of the temperaturedependent $\Delta G_{\text {form }}$ of reaction products during oxidation can greatly help the screening of MAX phases capable of withstanding high-temperature oxidizing conditions. We use the proposed high-throughput scheme to calculate temperature-dependent $\Delta G_{\text {form }}$ of 30 MAX phases with 211 stacking. The model uses the $0 \mathrm{~K}$ formation enthalpies $\Delta H_{\text {form }}$ [0 K; see Supplementary Tables 28] of $\mathrm{M}_{2} \mathrm{AC}(\mathrm{M}=\mathrm{Sc}, \mathrm{Y}, \mathrm{Ti}, \mathrm{Zr}, \mathrm{Hf}, \mathrm{V}, \mathrm{Nb}, \mathrm{Ta}, \mathrm{Cr}, \mathrm{Mo}, \mathrm{Mn}, \mathrm{Fe}, \mathrm{Co}, \mathrm{Ni}$, and $\mathrm{Cu} ; \mathrm{A}=\mathrm{Al}$, and $\mathrm{Si}) \mathrm{MAX}$ phases and elemental $\Delta G_{\mathrm{i}}$ from experiments to estimate $\Delta G_{\text {form }} \quad\left[=\Delta H_{\text {form }}+\Delta G^{\text {SISSO }}(T)\right.$ $-\sum_{\mathrm{i}} x_{\mathrm{i}} \Delta G_{\mathrm{i}}(T)$ ] at elevated temperatures; here $x$ is the stoichiometric weight of each element in the compound, $\Delta H_{\text {form }}$ is the formation enthalpy; and $\Delta G^{\text {SISSO }}$ is SISSO predicted entropic contribution to the $\Delta G_{\text {form }}{ }^{21}$. We note that the calculation of the finite-temperature phase stability of just one system may take millions of supercomputing CPU-hours, and months of actual calculation time, as demonstrated in work by a subset of these authors in the investigation of the phase stability in the $\mathrm{Ti}_{2} \mathrm{AlC}$ $\mathrm{Cr}_{2}$ AlC quaternary system ${ }^{19}$.

The $\Delta G_{\text {form }}$ for aluminum- and silicon-based MAX phases is shown as a heat map in Fig. 2a, b, respectively for $300 \mathrm{~K}-2000 \mathrm{~K}$ temperature range. The $\Delta G_{\text {form }}$ for $M_{2} A I C$ and $M_{2} S i C$ is arranged as increasing valence electron count (VEC) across the period in the periodic table for $\mathrm{M}$ from group III to XI with VEC of 3-11 [(III=Sc, $\mathrm{Y}), 4(\mathrm{IV}=\mathrm{Ti}, \mathrm{Zr}, \mathrm{Hf}), 5(\mathrm{~V}=\mathrm{V}, \mathrm{Nb}, \mathrm{Ta}), 6(\mathrm{Vl}=\mathrm{Cr}, \mathrm{Mo}), 7(\mathrm{VII}=\mathrm{Mn}), 8$ $(\mathrm{VIII}=\mathrm{Fe}), 9(\mathrm{IX}=\mathrm{Co}), 10(\mathrm{X}=\mathrm{Ni})$, and $11(\mathrm{XI}=\mathrm{Cu})]$. The $\Delta G_{\text {form }}$ shows decreasing trend in stability with increase in valence electron counts. The $\mathrm{Fe}_{2} \mathrm{AlC}, \mathrm{Co}_{2} \mathrm{AlC}, \mathrm{Ni}_{2} \mathrm{AlC}, \mathrm{Cu}_{2} \mathrm{AlC} \mathrm{MAX}$ phases with higher VEC do not exist as they decompose to competing phases ${ }^{2}$, which further confirms our results. In addition to highlighting a relationship between the thermodynamic stability of MAX phases with VEC, we show the temperature-dependent $\Delta G_{\text {form }}$ of $\mathrm{Ti}_{2} \mathrm{AC}$ $(\mathrm{A}=\mathrm{Al}, \mathrm{Si})$ and other possible binary phases in Supplementary Tables 3,5-7. The jump in $\Delta G_{\text {form }}$ at Ta-to- $C r$ and Ni-to-Cu is clearly visible with increasing VEC in Fig. 2a, b. This arises from near halffilling of $\mathrm{d}$-states in $\mathrm{Cr}$, and complete filling of non-bonding $\mathrm{d}$ states in $\mathrm{Cu}$. The $\Delta G_{\text {form }}$ also shows weakly separated stability regions with respect to temperature at $600 \mathrm{~K}$, i.e., below $600 \mathrm{~K}$ and over $600 \mathrm{~K}$ (see Supplementary Fig. 2). The change in the $\Delta G_{\text {form }}$ at higher temperatures implies an interplay of temperaturedependent enthalpy and entropic contributions. The accuracy of the SISSO model in predicting $\Delta G_{\text {form }}$ of binary oxides and MAX phases shows good agreement between predicted and experimentally known Ti-O phases as shown in Fig. 1. Similarly, we show the heat map of $\mathrm{M}_{2} \mathrm{SiC} \Delta G_{\text {form }}$, where $\mathrm{M}=\mathrm{Sc}, \mathrm{Y}, \mathrm{Ti}, \mathrm{Zr}, \mathrm{Hf}, \mathrm{V}, \mathrm{Nb}, \mathrm{Ta}$, $\mathrm{Cr}, \mathrm{Mo}, \mathrm{Mn}, \mathrm{Fe}, \mathrm{Co}, \mathrm{Ni}$ and $\mathrm{Cu}$, for the temperature range $300 \mathrm{~K}-2000 \mathrm{~K}$. The fast assessment of $\Delta G_{\text {form }}$ using SISSO will allow us to quickly scan the thermodynamic stability of MAX phases in particular, and a wider range of materials in general.

The $\Delta G_{\text {form }}$ for the different MAX phases in Fig. $2 a-b$ is a thermodynamically defined quantity that indicates the intrinsic stability of different MAX phases--relative to constituent elements--as a function of temperature. This just verifies whether the MAX phases are stable with regards to their constituent elements. We have discussed in the later part of the manuscript that analysis purely based on Gibb's stability could be misleading. Therefore, results in Fig. 2 should be seen as the part of story. However, as guide to eyes, we provide $\Delta G_{\text {form }}$ for competing phases in Fig. $2 \mathrm{c}-\mathrm{d}$ for $\mathrm{Ti}_{2} \mathrm{AlC}$ and $\mathrm{Ti}_{2} \mathrm{SiC}$, respectively. The $\Delta G_{\text {form }}$ analysis of 211 MAX phases allows us to set up two-fold hypothesis to test the proposed high-throughput framework(1) Can the predicted energies be used to assess oxidation behavior (reaction products and relative stability of competing 


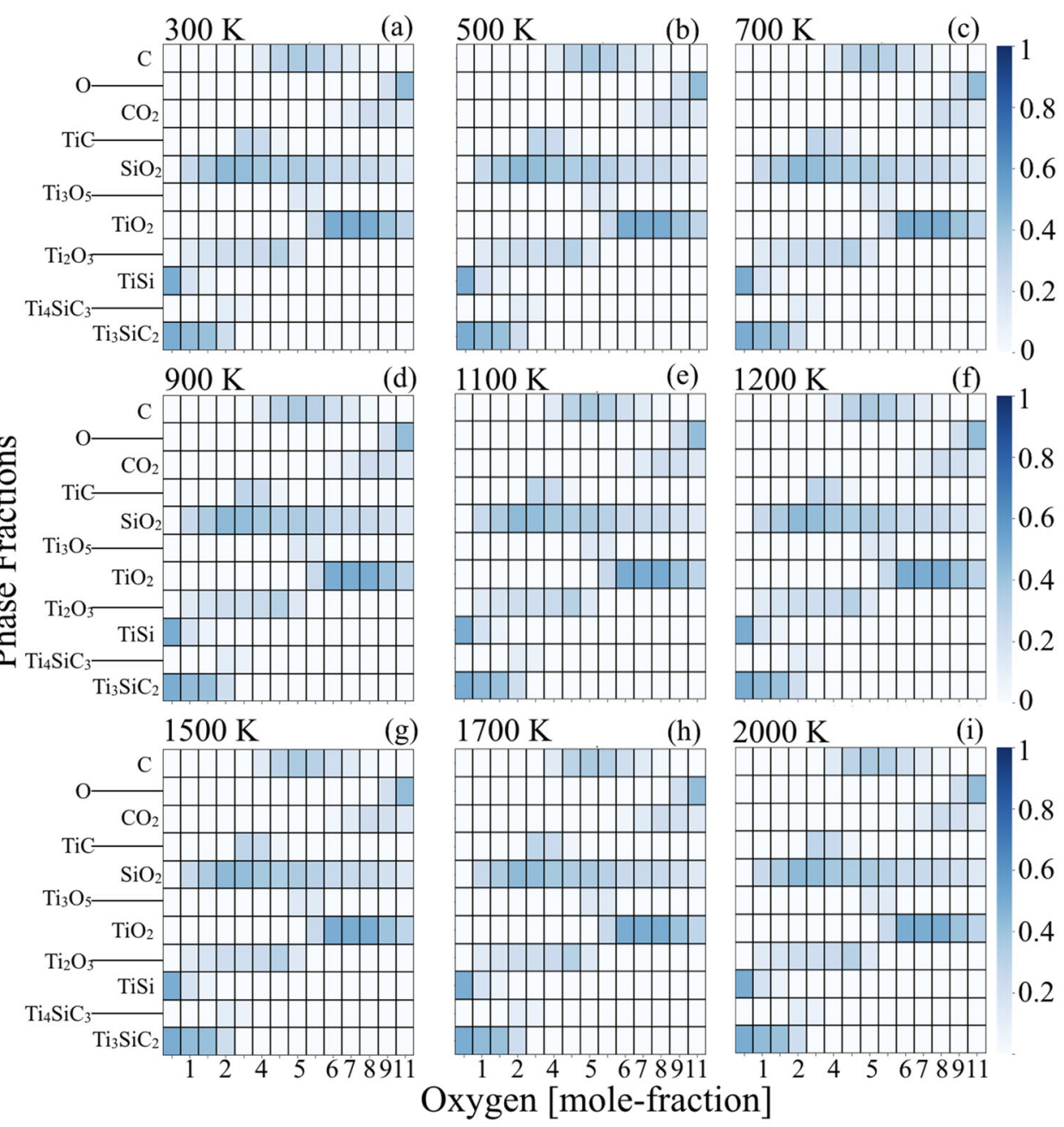

Fig. 3 Competing phases and phase-fraction of $\mathrm{Ti}_{2} \mathrm{SiC}+\mathrm{O}_{2} \mathrm{MAX}$ phase. a-i Phase fractions of $\left[\mathrm{Ti}_{2} \mathrm{SiC}+\mathrm{O}_{2}\right]$ reaction products at different temperatures with changing molar percent oxygen (0-11 moles). The color gradient (shades of blue) shows molar phase fractions. Blank spot [white (0)] suggests no phases. Note that $\mathrm{Ti}_{2} \mathrm{SiC}$ never belongs to the convex hull, which has zero phase fraction at all oxygen mole fractions.

phases) at higher temperatures, and (2) are we able to reproduce correct trends as experiments for the selected MAX phases.

Keeping this in mind, we choose systems with opposite characteristics-(a) stable $\mathrm{M}_{2} \mathrm{AlC}$, e.g., $\mathrm{Ti}_{2} \mathrm{AlC} / \mathrm{Cr}_{2} \mathrm{AlC}$, and metastable $\mathrm{M}_{2} \mathrm{SiC}$, e.g., $\mathrm{Ti}_{2} \mathrm{SiC}$-we note that the latter is thermodynamically stable against decomposition into its constituent elements but should not belong to the convex hull at any temperature and under any oxidation condition. We show that for both the cases, we could correctly characterize the thermodynamic stability of competing phases and chemical activity of elements at higher temperatures. All possible (thermodynamically stable) binary/ternary phases are included in this work, which is based on convex-hull algorithm used both by OQMD ${ }^{27}$ and AFLOW $^{30}$.

Oxidation analysis of Ti2SiC, Ti2AIC, and Cr2AIC MAX phases

The oxidation reaction at the interface of any alloy and oxide layer is the result of a phase selection process, in which the most favorable products of this process tend to be those close to the lowest (free) energy hyper-surface (or convex hull). The $0 \mathrm{~K}$ density-functional theory (DFT)-derived free energies and enthalpies of MAX phases as well as other competing phases are corrected for entropic contributions using our machine-learningbased high-throughput framework.
The oxidation behavior of of $\mathrm{Ti}_{2} \mathrm{SiC}+\mathrm{O}_{2}$ is analyzed and the thermodynamically competing reaction products are shown in the heat map in Fig. 3. The color bar from 0-1 shows the molar fraction of each phase. We also found that the hypothetical $\mathrm{Ti}_{2} \mathrm{SiC}$ MAX phase is intrinsically stable $e^{31-34}$ but experimentally not yet been realized due to higher stability of other thermodynamically competing phases in the complex $\mathrm{Ti}-\mathrm{Si}-\mathrm{C}$ phase diagram ${ }^{35}$. At the onset of oxidation process, $\mathrm{a}-\mathrm{SiO}_{2}$ forms, which is the most stable oxide that appears at all temperatures and all oxygen molarconcentrations. Other phases to form are $\mathrm{Ti}_{2} \mathrm{O}_{3}, \mathrm{Ti}_{3} \mathrm{SiC}_{2}, \mathrm{Ti}_{4} \mathrm{SiC}_{3}$, and TiSi. At higher oxygen concentration, $\mathrm{Ti}_{3} \mathrm{SiC}_{2}$ and $\mathrm{Ti}_{4} \mathrm{SiC}_{3}$ further transforms into $\mathrm{TiC}$ to maintain $\mathrm{Si}$ supply required for $\mathrm{a}$ $\mathrm{SiO}_{2}$ formation and completely disintegrates into a-SiO $/ 2 \mathrm{TiC} / \mathrm{C} /$ $\mathrm{Ti}_{2} \mathrm{O}_{3}$ as shown in Table 1 . This can be seen by reduced amount of another MAX phase with smaller $\mathrm{Si}$ content, namely $\mathrm{Ti}_{3} \mathrm{SiC}_{2}$ and $\mathrm{Ti}_{4} \mathrm{SiC}_{3}$ phases in Fig. $3 . \mathrm{Ti}_{2} \mathrm{O}_{3}$ further transforms into $\mathrm{TiO}_{2}$ at high oxygen concentrations. We can also see in Fig. 3 and Supplementary Table 3 that $\mathrm{Ti}_{3} \mathrm{O}_{5}$ and $\mathrm{Ti}_{2} \mathrm{O}_{3}$ have competing $\Delta G_{\text {form }}$, therefore, depending on phase-fraction size $\mathrm{Ti}_{2} \mathrm{O}_{3}$ disappears at some temperatures for low oxygen content. However, for the high oxygen contents, $\mathrm{Ti}_{3} \mathrm{SiC}_{2}, \mathrm{Ti}_{4} \mathrm{SiC}_{3} \mathrm{Ti}_{3} \mathrm{O}_{5}$, and $\mathrm{Ti}_{2} \mathrm{O}_{3}$ disintegrate to pave the way to the formation of more stable rutile phase, i.e., $\mathrm{TiO}_{2}$. Note that $\mathrm{Ti}_{2} \mathrm{SiC}$ never belongs to the convex hull, i.e., $\mathrm{Ti}_{2} \mathrm{SiC}$ phase fraction is "zero" for all oxygen mole percent for the full temperature range. The absence of $\mathrm{Ti}_{2} \mathrm{SiC}$ in the heat map in Fig. 3 


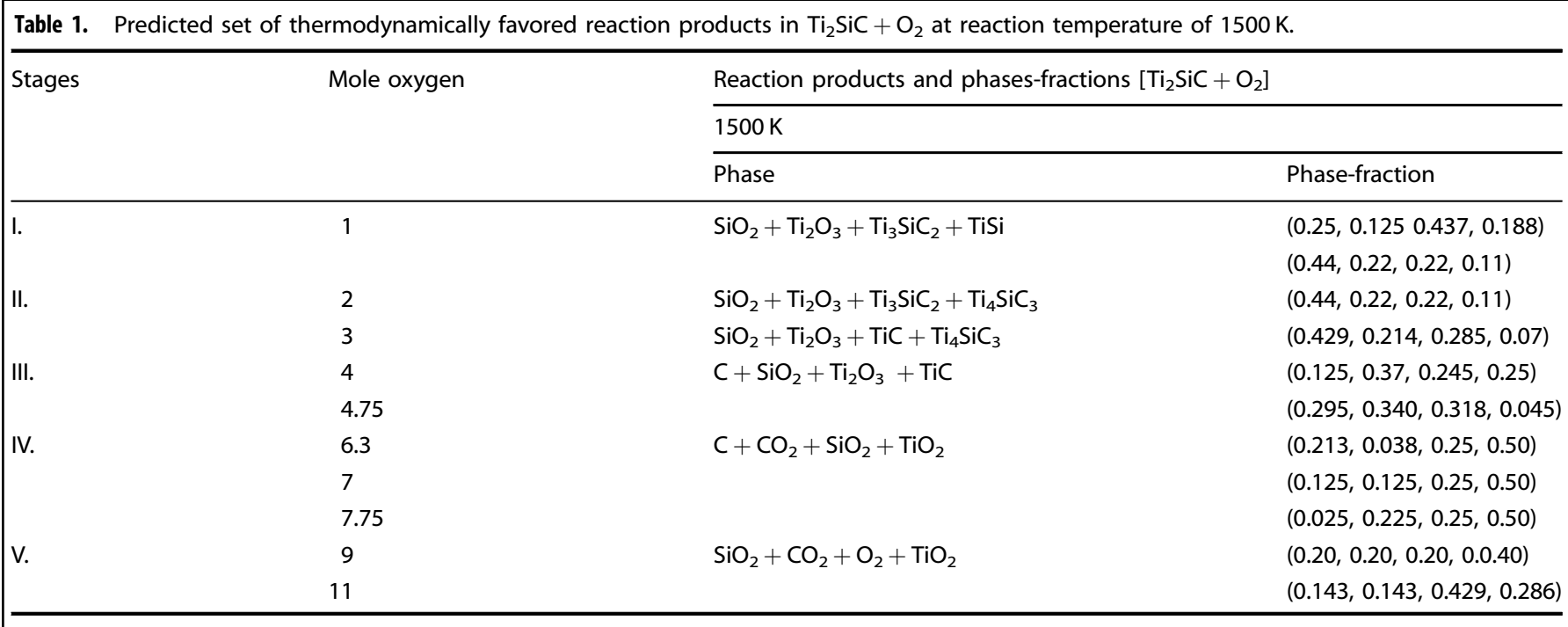

The GCLP minimizes SISSO predicted grand-canonical $\Delta G_{\text {form }}$ (see Supplementary Tables 2,3 , and 6) to estimate possible phase-fractions.

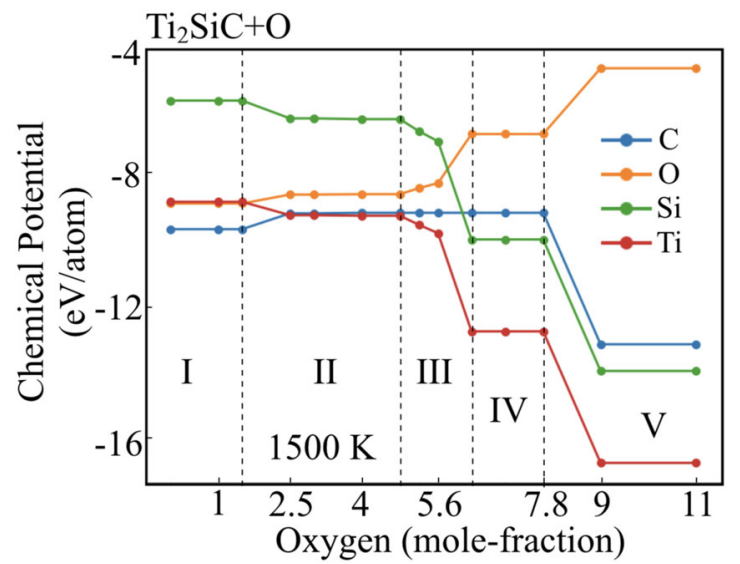

Fig. 4 Chemical activity of elements during oxidation process. Oxidation reaction chain showing change in chemical potential of $\mathrm{Ti}_{2} \mathrm{SiC}$ as a function of changing molar percent oxygen at $1500 \mathrm{~K}$. On oxidation, the partial chemical potentials of $\mathrm{Ti} / \mathrm{Si} / \mathrm{C}$ reduce while the chemical potential of invading $\mathrm{O}_{2}$ increases.

further confirms this robustness of our approach in predicting correct thermodynamic behavior of $\mathrm{Ti}_{2} \mathrm{SiC} \mathrm{MAX}$ phase.

Thermodynamically feasible oxidation reaction products predicted using GCLP analysis at $1500 \mathrm{~K}$ for $x . \mathrm{Ti}_{2} \mathrm{SiC}+y \cdot \mathrm{O}_{2}$ at varying oxygen concentrations are shown in Table 1. The reaction product of $x$ moles of $\mathrm{Ti}_{2} \mathrm{SiC}$ and $y$ moles of $\mathrm{O}_{2}$ can qualitatively be written for selective oxidation of $\mathrm{Ti}$ or $\mathrm{Si}$ as:

$x \cdot \mathrm{Ti}_{2} \mathrm{SiC}+y \cdot \mathrm{O}_{2} \rightarrow x\left(\mathrm{Ti}_{3} \mathrm{Si}_{1-x} \mathrm{C}_{2}+\mathrm{Ti}_{4} \mathrm{Si}_{1-x} \mathrm{C}_{3}\right)+y \cdot \mathrm{SiO}_{2}$,

or

$x \cdot \mathrm{Ti}_{2} \mathrm{SiC}+y \cdot \mathrm{O}_{2} \rightarrow \mathrm{Ti}_{3(1-x)} \mathrm{Si}_{1-x} \mathrm{C}_{2}+\mathrm{Ti}_{4(1-x)} \mathrm{Si}_{1-x} \mathrm{C}_{3}+\mathrm{TiO}_{2}$.

At high enough oxygen content, $\mathrm{TiC}$ further breaks away and $\mathrm{C}$ diffuses through rutile layer $\left(\mathrm{TiO}_{2}\right)$ and oxidizes into $\mathrm{CO}_{2}$, i.e.,

$\mathrm{Ti}_{2} \mathrm{SiC}+\mathrm{O}_{2} \rightarrow \mathrm{Ti}_{3} \mathrm{SiC}_{2}+\mathrm{Ti}_{4} \mathrm{SiC}_{3}+\mathrm{Ti}_{2} \mathrm{O}_{3} \rightarrow \mathrm{SiO}_{2}+\mathrm{TiO}_{2}+\mathrm{CO}_{2}+\mathrm{O}_{2}$

The chemical activity of constituent elements of the $\mathrm{Ti}_{2} \mathrm{SiC}+\mathrm{O}_{2}$ during oxidation process at $1500 \mathrm{~K}$ are shown in Fig. 4. The (partial) chemical potential of $(\mathrm{Ti}, \mathrm{Al}, \mathrm{C}, \mathrm{O})$ is calculated for an open system using unknown molar concentration of reaction products by mixing of grand-canonical $\Delta G_{\text {form }}$ at $1500 \mathrm{~K}$. The reaction chain is associated with the reductions in the partial chemical potentials of $\mathrm{Ti}, \mathrm{Si}$, and $\mathrm{C}$, but increase in the chemical potential of $\mathrm{O}$ with increasing oxygen content. The higher $\mathrm{Ti} / \mathrm{Si} / \mathrm{C}$ activity at the early oxidation stage is directly related to their partial chemical potentials. Two chemical potentials zones in Fig. 4 with increasing oxygen content are identified-(a) slowly varying (I-III); and (b) sharp changing (IV-V). The sharp change in chemical potential occurs in the region IV-V as $\mathrm{Ti}_{3} \mathrm{SiC}_{2} / \mathrm{Ti}_{4} \mathrm{SiC}_{3} / \mathrm{TiC}$ completely disintegrates by then, moreover, $\mathrm{C}$ oxidizes to form gaseous $\mathrm{CO}_{2}$. The occurrence of $\mathrm{C}$ and $\mathrm{CO}_{2}$ at higher temperature suggests loss of carbon. The predicted trend in chemical potential suggests increased oxygen activity at higher oxygen content.

In Fig. 5, we analyze the oxidation behavior of $\mathrm{Ti}_{2} \mathrm{AlC}$ and show the heat map of the molar phase-fractions of $\mathrm{Ti}_{2} \mathrm{AIC}+\mathrm{O}_{2}$ reaction product (the color bar on right represents the molar percent, or phase fraction, of each phase). The heat map shows the presence of $\mathrm{Al}_{2} \mathrm{O}_{3}$ at all oxygen mole fractions and for 300-2000 K, whereas, different $\mathrm{Ti}-\mathrm{O}$ phases are observed at low (TiO), intermediate (TiO, $\left.\mathrm{Ti}_{2} \mathrm{O}_{3}, \mathrm{Ti}_{3} \mathrm{O}_{5}\right)$, and high $\left(\mathrm{TiO}_{2}\right)$ oxygen contents. At the onset of oxidation process $\mathrm{Al}_{2} \mathrm{O}_{3}, \mathrm{Ti}_{3} \mathrm{AlC}_{2}$, and TiO forms first, which is followed by the reaction of oxygen with $\mathrm{Ti}_{3} \mathrm{AlC}_{2}$ that gradually transforms to TiC. At high oxygen contents, the MAX phase eventually disintegrates completely into solid $\mathrm{Al}_{2} \mathrm{O}_{3}$ and $\mathrm{TiO}_{2}$, and gaseous $\mathrm{CO}_{2}$ phase.

The predicted oxidation reaction chain for $\mathrm{Ti}_{2} \mathrm{AIC}$ at $1500 \mathrm{~K}$ is shown in Table 2 . The reaction table shows thermodynamically stable oxidation reaction products at varying oxygen mole fractions. The molar-oxygen content is varied to show its effect on reaction products, which represents the exposure time of the alloy to static air in experimental conditions. The reaction products of the chemical process during the selective oxidation of $\mathrm{Al}$ or $\mathrm{Ti}$ in $\mathrm{Ti}_{2} \mathrm{AlC}$ can be written as:

$4 \mathrm{Ti}_{2} \mathrm{AIC}+3 y \cdot \mathrm{O}_{2} \rightarrow 4 \mathrm{Ti}_{2} \mathrm{Al}_{1-x} \mathrm{C}+2 \mathrm{y} \cdot \mathrm{Al}_{2} \mathrm{O}_{3}$,

and

$\mathrm{Ti}_{2} \mathrm{AlC}+2 \mathrm{y} \cdot \mathrm{O}_{2} \rightarrow 2 \mathrm{Ti}_{2-2 x} \mathrm{AlC}+2 y . \mathrm{TiO}_{2}$.

Considering longer exposure time to static air, $\mathrm{C}$ diffuses through $\mathrm{TiO}_{2}$ and oxidizes into $\mathrm{CO}_{2}-$

$\mathrm{Ti}_{2} \mathrm{AlC}+\mathrm{O}_{2} \rightarrow \mathrm{Al}_{2} \mathrm{O}_{3}+\mathrm{TiO}_{2}+\mathrm{CO}_{2}$.

i.e., $\mathrm{C}$ from $\mathrm{Ti}-\mathrm{C}$ diffuses through the mixed Ti-oxides layer and oxidize. The diffusion of $\mathrm{Ti}$ to the surface and $\mathrm{O}$ into the MAX 

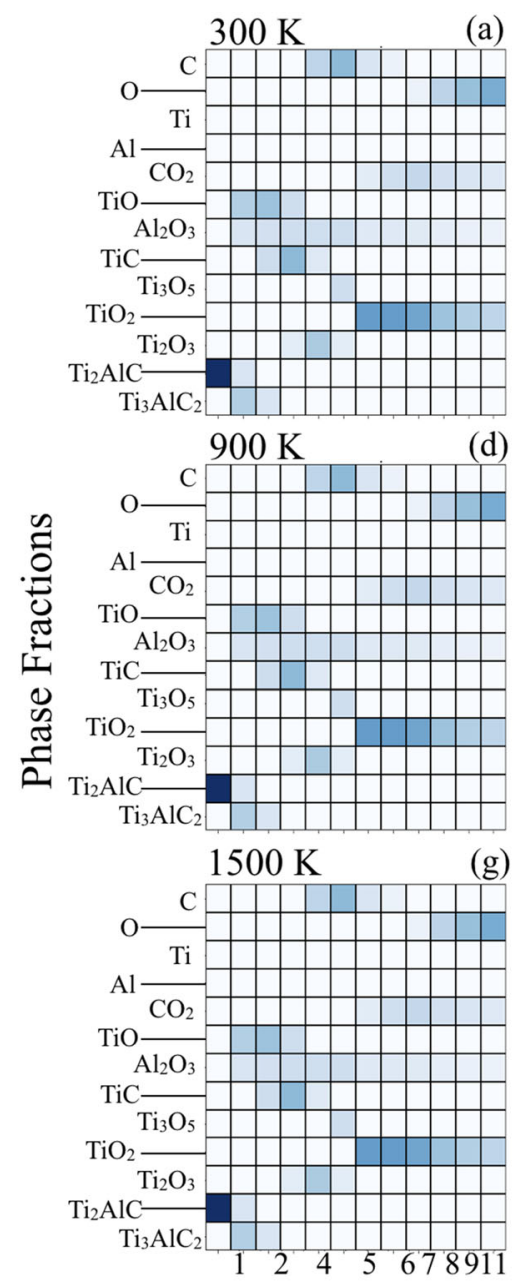

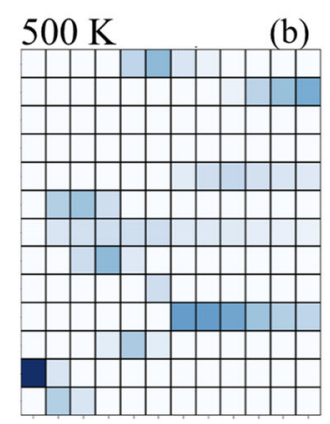

$1100 \mathrm{~K}$

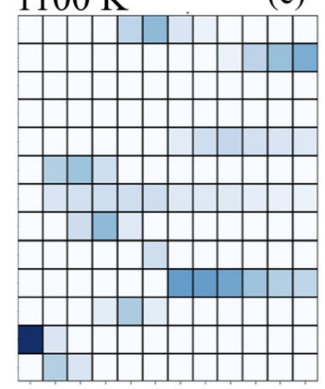

$1700 \mathrm{~K}$

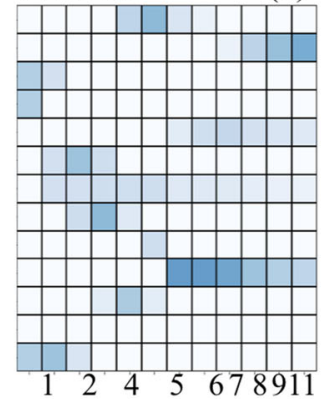

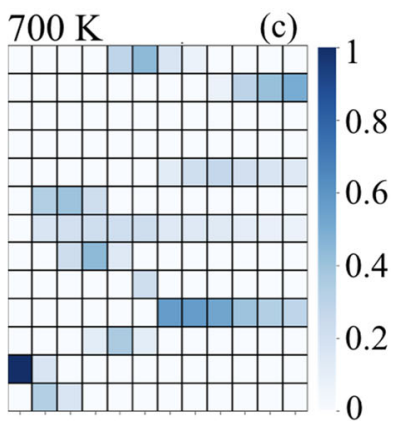

(f)

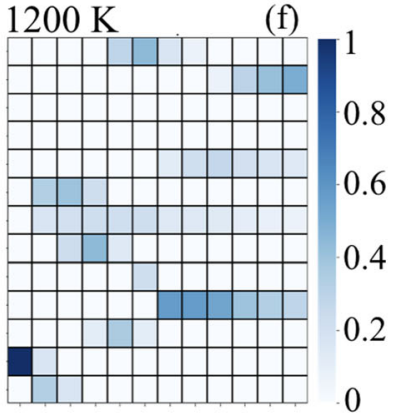

(i)

$2000 \mathrm{~K}$

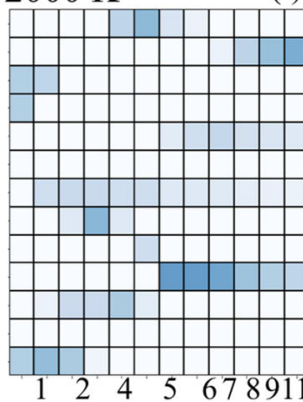

0.8

0.6

0.4

.2

0.8

0.6

0.4

0.2

0

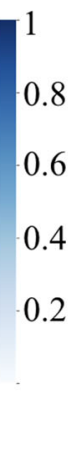

Fig. 5 Competing phases and phase-fraction of $\mathrm{Ti}_{2} \mathbf{A I C}+\mathrm{O}_{2} \mathbf{M A X}$ phase. a-i Phase fractions of $\left[\mathrm{Ti}_{2} \mathrm{AlC}+\mathrm{O}_{2}\right]$ reaction product at different temperature with changing molar percent oxygen (1-11 moles). The color gradient (shades of blue) shows molar phase fractions. Blank spot [white (0)] suggests no phases present.

phase or oxidation product during the oxidation process works as the rate-limiting condition.

More importantly, $\mathrm{Al}_{2} \mathrm{O}_{3}$ is seen at all temperatures and all oxygen concentrations due to the high chemical activity of $\mathrm{Al}$, see Fig. 5, as well as the very exothermic nature of the $\mathrm{Al}_{2} \mathrm{O}_{3}$ phase itself. The weak metallic bonding between Ti-Al can also contribute to the increased $\mathrm{Al}$ diffusivity ${ }^{36}$. The formation of $\mathrm{Al}_{2} \mathrm{O}_{3}$ results into $\mathrm{Al}$ depletion in $\mathrm{Ti}_{2} \mathrm{AlC}$ substrate at the early stage oxidation. This in turn leads to the decomposition of the MAX phases into $\mathrm{TiO}, \mathrm{Al}_{2} \mathrm{O}_{3}$, and $\mathrm{Ti}_{3} \mathrm{AlC}_{2}{ }^{28}$ at low oxygen concentration. This indicates that $\mathrm{Ti}$ and $\mathrm{Al}$ are the first oxidizing elements when $\mathrm{Ti}_{2} \mathrm{AlC}$ is exposed to ambient air at elevated temperatures. On further increasing the oxygen concentrations, the $\mathrm{Al}_{2} \mathrm{O}_{3}$ oxide scale remains stable compared to other oxides as partial pressure to form $\mathrm{Al}_{2} \mathrm{O}_{3}$ is much lower than of $\mathrm{TiO}_{2}{ }^{35}$. The weaker binding of Al with $\mathrm{C}$ or $\mathrm{Ti}$ in $\mathrm{Ti}_{2} \mathrm{AlC}^{37,38}$ and better Al diffusion ${ }^{36}$ eases the $\mathrm{Al}_{2} \mathrm{O}_{3}$ growth ${ }^{39}$. Al diffusion becomes easier at higher temperature that helps $\mathrm{Al}_{2} \mathrm{O}_{3}$ to grow further. The better thermodynamic stability of $\mathrm{Al}_{2} \mathrm{O}_{3}$ compared to other phases (see Supplementary Table 5) during oxidation of $\mathrm{Ti}_{2} \mathrm{AlC}$ also helps in stabilizing $\mathrm{Al}_{2} \mathrm{O}_{3}$ at elevated temperatures. The $\mathrm{C}$ and $\mathrm{CO}_{2}$ appear as the reaction products at higher temperature, which suggests $C$ loss and the evaporation of $\mathrm{CO}_{2}$ from the oxide scale ${ }^{40}$. The reaction product of $\mathrm{Ti}_{2} \mathrm{AIC}$ oxidation reaction correctly reproduces experimentally observed phase-fractions.
We show that using proposed high-throughput scheme that combines Gibbs free energies useful to predict high-temperature reaction paths without doing expensive DFT calculations. The approach is general, and can be used to assess the oxidation stability of arbitrary inorganic crystalline solids. Among the alumina-forming MAX phases, $\mathrm{Ti}_{2} \mathrm{AlC}$ is one of the most widely studied, and it is, by far, the most attractive for practical applications because it forms protective oxide layer that is resistant to thermal cycling ${ }^{28}$. The chemical activity of $\mathrm{Al}$ in $\mathrm{Ti}_{2} \mathrm{AIC}$ are large enough to result in preferential oxidation of $\mathrm{Al}$ into protective a $\mathrm{a}-\mathrm{Al}_{2} \mathrm{O}_{3}$ passivating layer ${ }^{28}$. Therefore, we choose to test the oxidation behavior of $\mathrm{Ti}_{2} \mathrm{AIC}$ MAX phase to establish the applicability of proposed ML-based high-throughput scheme.

We plot the chemical activity of constituent elements of $\mathrm{Ti}_{2} \mathrm{AlC}+\mathrm{O}_{2}$ oxidation process at $1500 \mathrm{~K}$ in Fig. 6 . The (partial) chemical potential of $(\mathrm{Ti}, \mathrm{Al}, \mathrm{C}, \mathrm{O})$ is calculated for an open system using unknown molar concentration of reaction products by mixing of grand-canonical $\Delta G_{\text {form }}$ for $300-2000 \mathrm{~K}$ (see Supplementary Fig. 5). The reaction chain is associated with the reductions in the partial chemical potentials of $\mathrm{Ti}, \mathrm{Al}$, and $\mathrm{C}$ but increase in the chemical potential of $\mathrm{O}_{2}$ with increasing oxygen content. Expectedly, the $\mathrm{Ti} / \mathrm{Al} / \mathrm{C}$ activity at the early oxidation stage comes out higher, which is directly related to the partial chemical potentials. Similar as in the case of $\mathrm{Ti}_{2} \mathrm{SiC}$, we could see two different zones of chemical potentials in Fig. 6, (a) slowly 
Table 2. Predicted set of thermodynamically favored reaction products in $\mathrm{Ti}_{2} \mathrm{AlC}+\mathrm{O}_{2}$ at reaction temperature of $1500 \mathrm{~K}$.

\begin{tabular}{|c|c|c|c|}
\hline \multirow[t]{3}{*}{ Stages } & \multirow[t]{3}{*}{$\begin{array}{l}\text { Mole- } \\
\text { oxygen }\end{array}$} & \multicolumn{2}{|c|}{$\begin{array}{l}\text { Reaction products and phases-fractions } \\
{\left[\mathrm{Ti}_{2} \mathrm{AlC}+\mathrm{O}_{2}\right]}\end{array}$} \\
\hline & & \multicolumn{2}{|l|}{$1500 \mathrm{~K}$} \\
\hline & & Phase & Phase-fraction \\
\hline \multirow[t]{2}{*}{ I. } & 1 & $\begin{array}{l}\mathrm{Al}_{2} \mathrm{O}_{3}+\mathrm{Ti}_{2} \mathrm{AlC}+ \\
\mathrm{Ti}_{3} \mathrm{AlC}_{2}+\mathrm{TiO}\end{array}$ & $(0.167,0.167,0.33,0.33)$ \\
\hline & 1.75 & $\begin{array}{l}\mathrm{Al}_{2} \mathrm{O}_{3}+\mathrm{Ti}_{3} \mathrm{AlC}_{2}+\mathrm{TiC} \\
+\mathrm{TiO}\end{array}$ & $(0.20,0.17,0.23,0.40)$ \\
\hline II. & 2.75 & $\begin{array}{l}\mathrm{Al}_{2} \mathrm{O}_{3}+\mathrm{Ti}_{2} \mathrm{O}_{3}+\mathrm{TiC}+ \\
\mathrm{TiO}\end{array}$ & $(0.22,0.11,0.44,0.22)$ \\
\hline \multirow[t]{2}{*}{ III. } & 4 & $\begin{array}{l}\mathrm{Al}_{2} \mathrm{O}_{3}+\mathrm{C}+\mathrm{TiC}+ \\
\mathrm{Ti}_{2} \mathrm{O}_{3}\end{array}$ & $\begin{array}{l}(0.214,0.285 \\
0.143,0.357)\end{array}$ \\
\hline & 4.75 & $\begin{array}{l}\mathrm{Al}_{2} \mathrm{O}_{3}+\mathrm{C}+\mathrm{Ti}_{3} \mathrm{O}_{5}+ \\
\mathrm{Ti}_{2} \mathrm{O}_{3}\end{array}$ & $(0.22,0.44,0.22,0.11)$ \\
\hline \multirow[t]{2}{*}{ IV. } & 6.3 & \multirow{2}{*}{$\begin{array}{l}\mathrm{Al}_{2} \mathrm{O}_{3}+\mathrm{C}+\mathrm{CO}_{2}+ \\
\mathrm{TiO}_{2}\end{array}$} & $(0.143,0.17,0.11,0.571)$ \\
\hline & 7 & & $(0.143,0.07,0.21,0.571)$ \\
\hline \multirow[t]{3}{*}{ V. } & 7.75 & \multirow{3}{*}{$\begin{array}{l}\mathrm{Al}_{2} \mathrm{O}_{3}+\mathrm{CO}_{2}+\mathrm{O}_{2}+ \\
\mathrm{TiO}_{2}\end{array}$} & $(0.133,0.266,0.07,0.53)$ \\
\hline & 9 & & $(0.10,0.20,0.30,0.40)$ \\
\hline & 11 & & $(0.071,0.14,0.50,0.286)$ \\
\hline
\end{tabular}

The GCLP minimizes SISSO predicted $\Delta G_{\text {form }}$ (see Supplementary Tables 4 5 , and 7) to estimate possible phase-fractions.

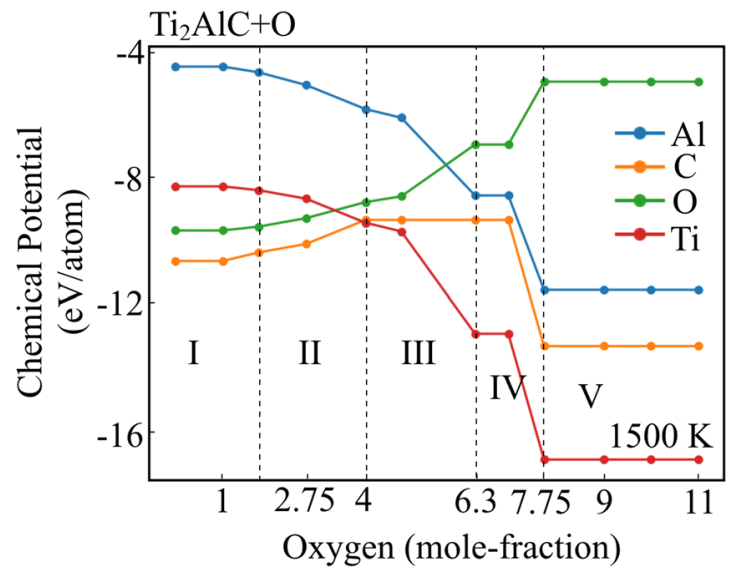

Fig. 6 Chemical activity of elements during oxidation process. Oxidation reaction chain showing change in chemical potential of $\mathrm{Ti}_{2} \mathrm{AlC}$ as a function of changing molar percent oxygen at $1500 \mathrm{~K}$. On oxidation, the partial chemical potentials of $\mathrm{Ti} / \mathrm{Al} / \mathrm{C}$ reduce while the chemical potential of invading $\mathrm{O}_{2}$ increases (see Supplementary Fig. 3).

varying region I-III; and (b) sharply changing region IV-V with increasing oxygen content. The sharp change in chemical potential in region IV-V occurs as $\mathrm{C}$ oxidizes into gaseous $\mathrm{CO}_{2}$. The occurrence of $\mathrm{C}$ and $\mathrm{CO}_{2}$ at higher temperature suggests loss of carbon. The calculated trend in chemical potential in Fig. 6 suggests increased oxygen activity at higher oxygen content (see Supplementary Fig. 5).

The low oxygen content regime, i.e., region I-II, replicates the shorter exposure time to oxygen. This region occurs below a critical thickness level of $\mathrm{Ti}_{2} \mathrm{AlC}$ substrate, also shown by schematic of wedge experiment in Supplementary Fig. 4b. In the oxygen rich region (IV-V; see Supplementary Fig. 3j), the $\mathrm{Ti}_{2} \mathrm{AIC}$ substrate has large surface to volume ratio, i.e., larger exposure to air/oxygen. The chemical activity of the oxygen significantly changes compared to low oxygen region I-III. As oxygen content increases, the $\mathrm{Ti}_{2} \mathrm{AlC}$ MAX phase decomposes into stable $\mathrm{TiO}_{2}, \mathrm{Al}_{2} \mathrm{O}_{3}$ and $\mathrm{CO}_{2}$ phases. In Fig. 6 , the oxidation of $\mathrm{Ti}_{2} \mathrm{AlC}$ lowers the chemical potential $\mathrm{Al}$ and $\mathrm{Ti}$, which results into increased outward diffusion of $\mathrm{Al}$ and $\mathrm{Ti}$. The lowered chemical potential with increasing oxygen content and weak Ti-Al bonding keep the constant supply of $\mathrm{Al}$ at all temperatures for the Al-O reaction. The chemical activity of $\mathrm{Al}$, as shown in Fig. 6 , is much higher than that of Ti and $\mathrm{C}$, suggesting that the formation of $\mathrm{Al}_{2} \mathrm{O}_{3}$ is a much faster process. Therefore, protective $\mathrm{Al}_{2} \mathrm{O}_{3}$ layers are formed quickly on $\mathrm{Ti}_{2} \mathrm{AlC}$ substrate and stops further degrading due to oxygen attack. $\mathrm{Al}_{2} \mathrm{O}_{3}$ formation is also preferred because of lower vapor pressure of $\mathrm{Al}$ with respect to $\mathrm{O}$ when compared to Ti with respect to $\mathrm{O}$. At low oxygen content (region I-III), the oxidized surface of the film is a mixture of the $\mathrm{Al}_{2} \mathrm{O}_{3}$, as well as $\mathrm{TiO}(\mathrm{I}), \mathrm{TiC}(\mathrm{I}), \mathrm{Ti}_{2} \mathrm{O}_{3}(\mathrm{I})$, and/or $\mathrm{Ti}_{3} \mathrm{O}_{5}$ (II) depending on exposure time or oxygen content to $\mathrm{O}_{2}$.

When compared to alumina-forming alloys ${ }^{41-43}$, MAX phases do experience different breakaway oxidation mechanisms after longterm exposure ${ }^{44}$ to static air. As soon as the Al-containing reservior exceeds a certain Al loss level, the reservoir decomposes into competing phases rather than remaining in an $\mathrm{Al}$-deficient form, which can not form anymore $\mathrm{Al}_{2} \mathrm{O}_{3}$.

To test our predictions of oxidation reaction mechansism for $\mathrm{Ti}_{2} \mathrm{AlC}$ under controlled oxygen exposure as predicted by our GCLP analysis in Table 2, we prepared wedge-shaped samples and performed breakaway oxidation at $1500 \mathrm{~K}$ temperature in the presence of static air. The oxidation tests are carried out in a box furnace (Carbolite, UK) (see the methods). The use of wedgeshaped samples to study breakaway oxidation have been applied successfully to FeCrAl-based alloys ${ }^{45}$. We used scanning electron microscopies (FE-SEM, Quanta 600 FEG, FEl, Oregon, USA) equipped with energy dispersive spectroscopy (EDS) to identify the microstructure and phases along the wedge. Electron microprobe analysis (EPMA) is used for a quantitative phase evaluation in the breakaway oxidation region in $\mathrm{Ti}_{2} \mathrm{AlC}$. The SEM sshows five distinct regions as also shown in Fig. 7 based on oxidation activity as marked:

I. Very thin protective $\mathrm{Al}_{2} \mathrm{O}_{3}$ oxide layer forms on the surface,

II. Small $\mathrm{Al}_{2} \mathrm{O}_{3}+\mathrm{TiO}_{2}$ nodules in this region, with no other phases except $\mathrm{Ti}_{2} \mathrm{AlC}$ substrate in the middle,

III. Mixed $\mathrm{Al}_{2} \mathrm{O}_{3}+\mathrm{TiO}_{2}$ oxides on the surface. Part of the $\mathrm{Ti}_{2} \mathrm{AIC}$ substrate survived with $\mathrm{Ti}_{3} \mathrm{AlC}_{2}$ phase according to EPMA,

IV. Mixed $\mathrm{Al}_{2} \mathrm{O}_{3}+\mathrm{TiO}_{2}$ oxide layer on the surface with pure $\mathrm{TiO}_{2}$ replacing the pure $\mathrm{Ti}_{2} \mathrm{AIC}$,

V. $\mathrm{Ti}_{2} \mathrm{AlC}$ at thin end is completely oxidized to $\mathrm{TiO}_{2}+\mathrm{Al}_{2} \mathrm{O}_{3}$, which is in agreement with our predictions in Fig. 7.

The five regions in Fig. 7 can further be categorized as low (I-III), intermediate (IV), and high (V) oxygen activity zones, which compares well with the highlighted regions in the chemical activity plot Fig. 6 (see Supplementary Fig. 3j) calculated at $1500 \mathrm{~K}$. The mixed oxide $\left(\mathrm{Al}_{2} \mathrm{O}_{3}+\mathrm{TiO}_{2}\right)$ in region III and IV is quite similar to the small nodules observed in region II. This indicates the start of nucleation that grows into large and continuous regions (also see Fig. 7, inset-b). We believe that the intermediate phase (III) plays a key role in the decomposition path from $\mathrm{Ti}_{2} \mathrm{AIC}$ to $\mathrm{TiO}_{2}$ and $\mathrm{Al}_{2} \mathrm{O}_{3}$. Therefore, the oxygen content is important at the onset of phase III to evaluate oxidation stability of different MAX phases because if onset is at higher $\mathrm{O}$ concentrations, the MAX phase is more stable. This is in agreement with the theoretically proposed reaction path in Table 2. Notably, our EPMA analysis in Fig. 7 (inset-a) on the wedge-shaped $\mathrm{Ti}_{2} \mathrm{AlC}$ sample, which oxidized at $1200^{\circ} \mathrm{C}$ for 30 minutes, shows that $\mathrm{Ti}_{2} \mathrm{AlC}$ decomposes into $\mathrm{Ti}_{3} \mathrm{AlC}_{2}$ and $\mathrm{TiC}$ (also marked in inset-a). For $\mathrm{Ti}_{3} \mathrm{AlC}_{2}$, the reported critical Al loss is $5.99 a t . \%{ }^{43}$, whereas Ti-C binary is believed to form due to the depletion of $\mathrm{Al}$ in the substrate ${ }^{46}$. A recent study also suggest the increase in volume fraction of $\mathrm{Ti}_{3} \mathrm{AlC}_{2}$ and $\mathrm{TiC}$ phases in the substrate in Region III. The thick oxide layer (mixed) in region III 


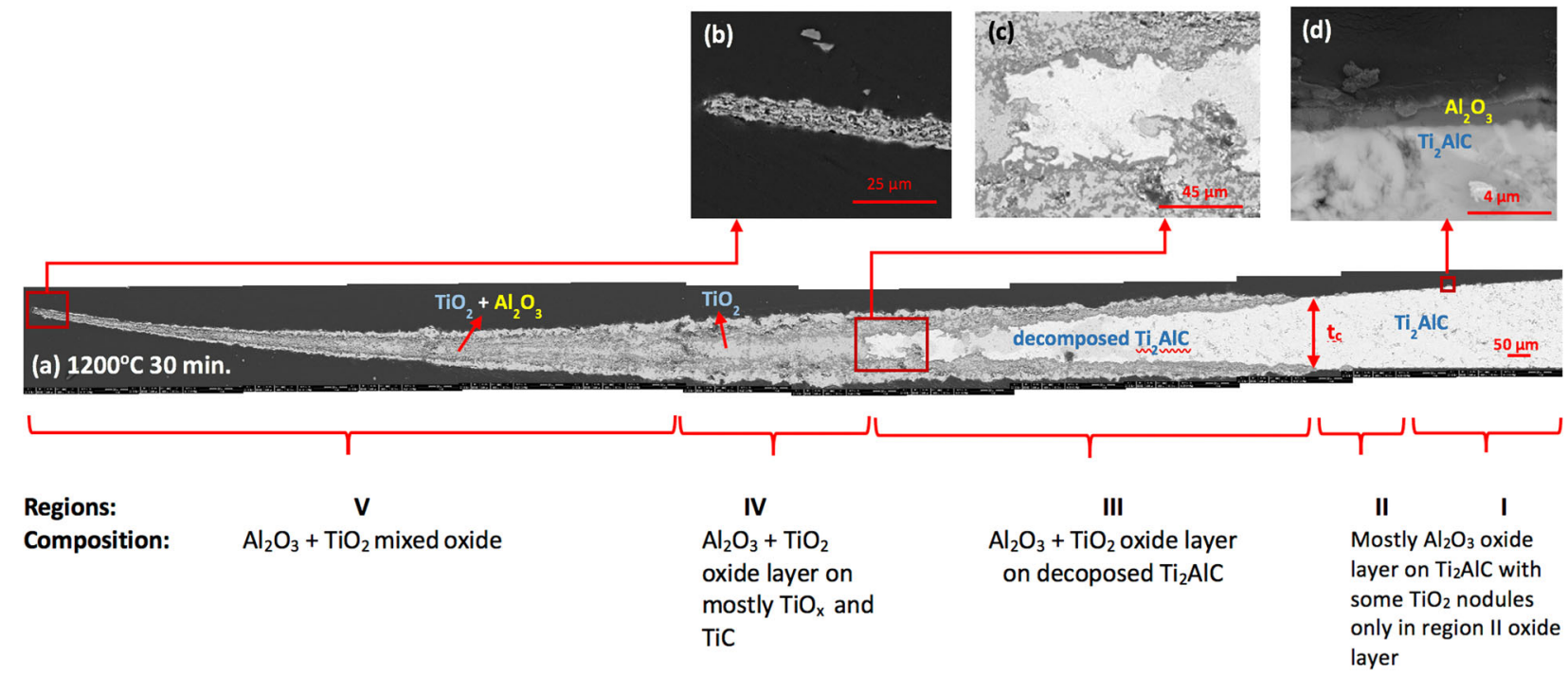

Fig. 7 Breakaway oxidation behavior of $\mathrm{Ti}_{2} \mathrm{AIC}$. (a) Backscattered Electron SEM images of selected wedge-shaped $\mathrm{Ti}_{2} \mathrm{AIC}$ oxidized at $1200{ }^{\circ} \mathrm{C}$ for $30 \mathrm{~min}$. Insert b, C, and d shows magnified tip, middle and end, respectively, of the wedge-shaped sample oxidized at $1200^{\circ} \mathrm{C}$ for 30 min.

conforms with the breakaway mechanism. The formation of Aldeficient $\mathrm{Ti}_{3} \mathrm{AlC}_{2}$ and $\mathrm{TiC}$ phases are leading factors for the mixed oxide layer formation. Our high-throughput study suggests the presence of mixed $\mathrm{Al}_{2} \mathrm{O}_{3}+\mathrm{TiO}_{2}$ oxide layer in region IV and region $\mathrm{V}$ as shown in Table I. The experiments on region IV and region $\mathrm{V}$ shows the presence of thick mixed oxide layer in Fig. 7. This is similar to the mixed oxide phase observed in region III. In region $\mathrm{V}$ (at the tip of the wedge sample), the fast Al depletion from $\mathrm{Ti}_{2} \mathrm{AlC}$ allows only mixed oxide layers, e.g., even very short exposure to static air at $1500 \mathrm{~K}$, the very tip of the wedge-shaped sample oxidizes to the mixed $\mathrm{Al}_{2} \mathrm{O}_{3}$ and $\mathrm{TiO}_{2}$ phase. Similar to the highthroughput predictions at higher oxygen content, experiments suggest that on longer exposure to oxygen, $\mathrm{O}_{2}$ will penetrate and react with $\mathrm{Ti}_{2} \mathrm{AlC}$, which will lead to gradual decomposition of $\mathrm{Ti}_{2} \mathrm{AlC}$ to $\mathrm{Ti}_{3} \mathrm{AlC}$ and $\mathrm{TiC}$ along with the formation of $\mathrm{Al}_{2} \mathrm{O}_{3}$ and $\mathrm{TiO}_{x}$ phases. The formation of $\mathrm{Al}_{2} \mathrm{O}_{3}\left(7.9 \times 10^{-6}-8.8 \times 10^{-6}{ }^{\circ} \mathrm{C}^{-1}\right)$ have outstanding match of thermal expansion with $\mathrm{Ti}_{2} \mathrm{AlC}$ $\left(9-9.6 \times 10^{-6}{ }^{\circ} \mathrm{C}^{-1}\right)$ compared to other MAX phases ${ }^{47}$, which makes $\mathrm{Ti}_{2} \mathrm{AlC}$ better candidate for high-temperature application.

Experiments indicates that the breakaway oxidation is possibly caused by gradual decomposition of Al-deficient $\mathrm{Ti}_{2} \mathrm{Al}_{1-x} \mathrm{C}$, to $\mathrm{Ti}_{3} \mathrm{AlC}_{2}$ and further to $\mathrm{TiC}$ and subsequent oxidation of those phases to form mixed oxide. To understand this, we perform direct calculations considering $(3.125 ; 6.25 ; 9.375)$ at.\% vacancy concentration in $\mathrm{Ti}_{2} \mathrm{AlC}$.

Given that oxygen diffuses into the bulk material via the $\mathrm{Al}_{2} \mathrm{O}_{3}$ grain-boundary channels, sub-interface oxidation would result into the formation and distributions of various phases according to the predicted reaction chain. This is, however, the less likely case as the diffusion of $\mathrm{Al}$ from within the $\mathrm{Ti}_{2} \mathrm{AlC}$ towards its interface is a faster process. As the latter happens, depletion of $\mathrm{Al}$ in $\mathrm{Ti}_{2} \mathrm{AIC}$ can result in decomposition of the MAX phase into energetically more favorable competing reaction products. We assess this possibility of $\mathrm{Ti}_{2}\left[\mathrm{Al}_{1-x} \mathrm{Va}_{x}\right] \mathrm{C}$ stability relative to the other competing phases.

Even though the $\Delta G_{\text {form }}$ for $\mathrm{Ti}_{2}\left[\mathrm{Al}_{1-x} \mathrm{Va}_{x}\right] \mathrm{C}$ in Fig. 8 suggests the intrinsic stability (i.e., negative heats of formation), it remains less stable when compared to competing phases, i.e., $\mathrm{Ti}_{2} \mathrm{AlC}(90.625$; 81.25; 71.875), $\mathrm{Ti}_{3} \mathrm{AlC}(3.125 ; 6.25 ; 9.375)$, and $\mathrm{Ti}_{3} \mathrm{AlC}_{2}$ (3.125; 6.25; 9.375) for all considered vacancy cases $-x_{\mathrm{vac}}(3.125 ; 6.25 ; 9.375)$ (all compositions are in at.\%). This indicates that Al-deficient $\mathrm{Ti}_{2} \mathrm{AlC}$ is not energetically favored and tends to decompose into $\mathrm{Ti}_{3} \mathrm{AlC}_{2}$. The predicted decomposition, however, depends on the energy barrier required to nucleate the precipitates of those phases,

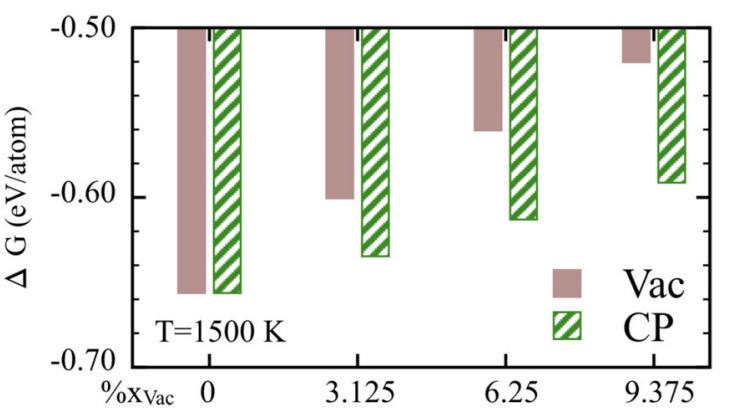

Fig. 8 Vacancy phase stability during breakaway oxidation of $\mathbf{T i}_{2}$ AIC. Calculated $\Delta G_{\text {form }}$ of Al-depleted $\mathrm{Ti}_{2}\left[\mathrm{Al}_{1-x} V \mathrm{a}_{x}\right] \mathrm{C}$, i.e., with vacancy, relative to the competing phases (CP) $\left(\mathrm{Ti}_{2} \mathrm{AIC}, \mathrm{Ti}_{3} \mathrm{AIC}\right.$, and $\left.\mathrm{Ti}_{3} \mathrm{AlC}_{2}\right)$ at $1500 \mathrm{~K}$ shows that $\mathrm{Ti}_{2}\left(\mathrm{Al}_{1-x} \mathrm{Va}_{x}\right) \mathrm{C}$ is energetically less stable. The configurational entropy term is included for vacancy cases using $\Delta S_{\text {config }}=-\left[\left(x_{\text {vac }} \ln x_{\text {vac }}+\left(1-x_{\text {vac }}\right) \ln \left(1-x_{\text {vac }}\right)\right)\right]$, here $x_{\mathrm{vac}}=(0.03125 ; 0.0625 ; 0.09375)$.

which is not easily accessible due computational complexity of the $\mathrm{Ti}_{2} \mathrm{AIC}$ supercells with vacancy. In spite of this, similar to the experiments, not only do we predict the formation of $\mathrm{Al}_{2} \mathrm{O}_{3}$ and $\mathrm{TiO}_{y}$ with increasing $\mathrm{O}_{2}$ but also the gradual decomposition of Aldeficient $\mathrm{Ti}_{2} \mathrm{AlC}$ into $\mathrm{Ti}_{3} \mathrm{AlC}$ and $\mathrm{TiC}$. Our experiments found $\mathrm{Al}$ deficiency of $\sim 5$ at.\% in $\mathrm{Ti}_{2} \mathrm{AlC}$ (see Supplementary Fig. 6) that leads to the breakaway oxidation, i.e., formation of alumina and titania, instead of a protective predominately $\mathrm{Al}_{2} \mathrm{O}_{3}$ oxide layer.

The Al deficiency further leads to the decomposition of $\mathrm{Ti}_{2} \mathrm{AIC}$ and the formation of $\mathrm{Ti}_{3} \mathrm{AlC}_{2}$, however, the traces of $\mathrm{Ti}_{3} \mathrm{AIC}$ and $\mathrm{Ti}_{3} \mathrm{AlC}_{2}$ precipitates are not discernable in Regions I and II. This could be either due to a high-energy barrier for nucleation of $\mathrm{Ti}_{3} \mathrm{SIC}_{2}$ that arrests the decomposition of the metastable $\mathrm{Ti}_{2}\left[\mathrm{Al}_{1-x} \mathrm{Va}_{x}\right] \mathrm{C}$, or $\mathrm{Ti}_{3} \mathrm{AIC}$ and $\mathrm{Ti}_{3} \mathrm{AlC}_{2}$ precipitates are formed below oxide/substrate interface in relatively smaller fractions and the phase-fraction remains well below the experimental detection limit.

In spite of some degree of disagreement between phase stability in vacancy-containing $\mathrm{Ti}_{2} \mathrm{AIC}$ with experiments, the relative shift in stability with respect to competing phases could be used as a metric for selection and/or screening of potentially promising Al-forming MAX compounds or alloys. In previous work $^{36}$, for example, we have discovered that alloying in the $A$ sublattice creates energetically favorable environment for the formation of vacancies, while at the same time benefitting from 


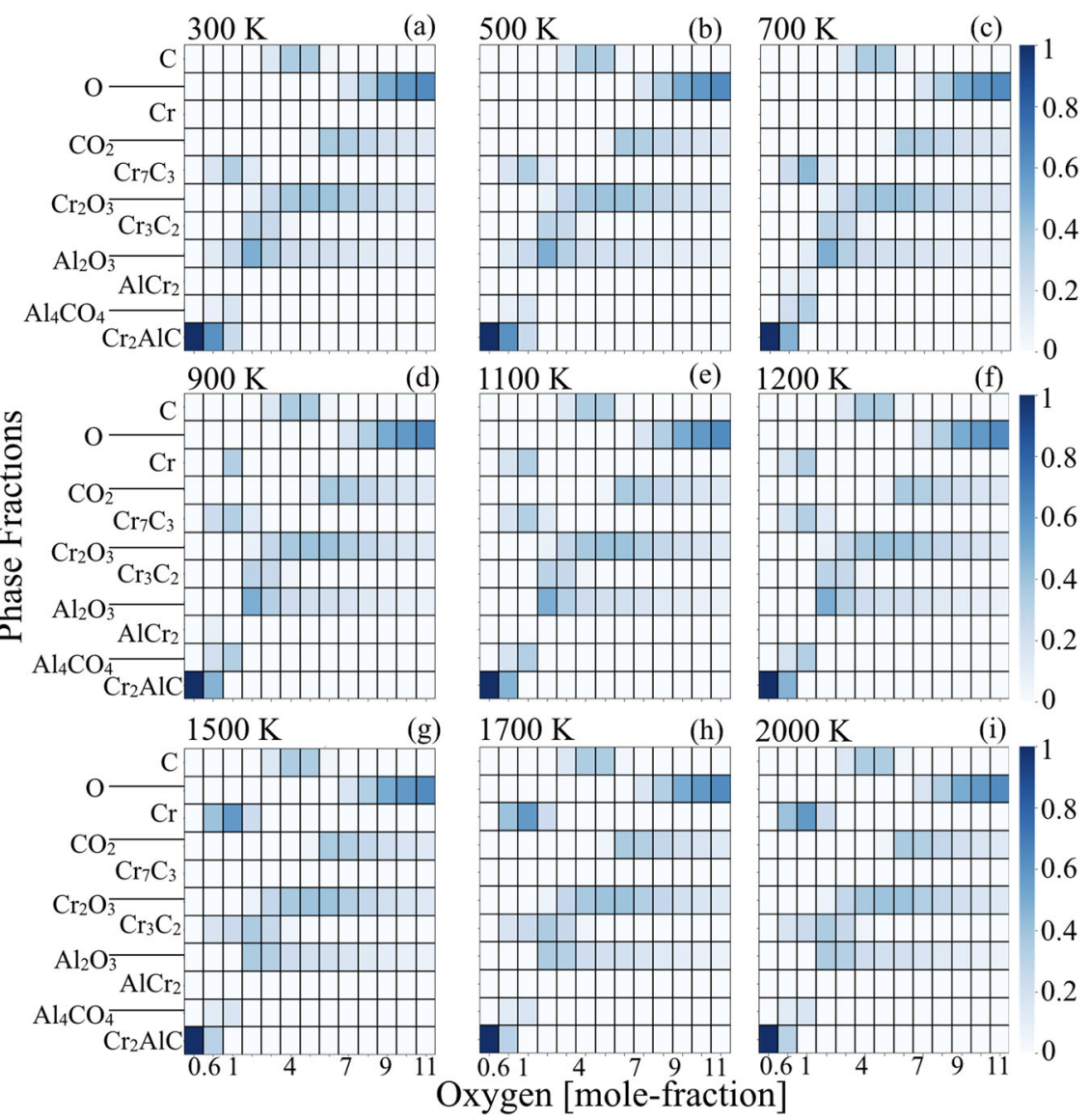

Fig. 9 Competing phases and phase-fraction of $\mathrm{Cr}_{2} \mathrm{AIC}+\mathrm{O}_{2}$ MAX phase. a-i Phase fractions of $\left[\mathrm{Cr}_{2} \mathrm{AlC}+\mathrm{O}_{2}\right]$ reaction product at different temperature with changing molar percent oxygen. Each block refers to specific oxygen molar content from 1-11 moles. The color gradient (shades of blue) shows molar phase fractions. Blank spot [white (0)] suggests no phases present.

the configurational entropic contributions. This would necessarily result in a delay to the onset of decomposition into competing phases once vacancies start to form in the A sublattice of Alcontaining MAX phases, for example. The search for alloys with reduced vacancy formation energy and fast vacancy mobility could guide the development of more oxidation resistant MAX alloys and compounds.

Prediction of oxidation behavior in $\mathrm{Cr}_{2} \mathrm{AIC}$ MAX phase-higher stiffness, smaller Vickers hardness, and machinable ${ }^{48}$, similar to $\mathrm{Ti}_{2} \mathrm{AlC}^{49}$, makes $\mathrm{Cr}_{2} \mathrm{AlC}$ an outstanding candidate for the hightemperature application. Lin et al. ${ }^{50}$ reported excellent oxidation resistance, which is probably due to the formation of protective $\mathrm{Al}_{2} \mathrm{O}_{3}$ and $\mathrm{Cr}_{2} \mathrm{O}_{3}$ layers as oxides. The oxidation is an important factor $^{28}$, however, we found no detailed discussion on $\mathrm{Cr}_{2} \mathrm{AlC}$. Therefore, we analyze the oxidation behavior of $\mathrm{Cr}_{2} \mathrm{AlC}$.

The heat map of the molar phase-fractions of $\mathrm{Cr}_{2} \mathrm{AlC}+\mathrm{O}_{2}$ reaction product in Fig. 9 (the color bar on right represents the molar percent, or phase fraction) at 300, 500, 700, 900, 1200, 1500, 1700 , and $2000 \mathrm{~K}$ for $0-11$ moles of oxygen content. We considered 13 thermodynamically most stable phases based on Gibbs formation energy, see Supplementary Fig. 7. Different $\mathrm{Cr}-$ based phases were observed: at low/intermediate $\left(\mathrm{Cr}_{7} \mathrm{C}_{3}, \mathrm{Cr}_{2} \mathrm{O}_{3}\right.$, $\left.\mathrm{Cr}, \mathrm{Cr}_{3} \mathrm{C}_{2}\right)$, intermediate $\left(\mathrm{Cr}_{7} \mathrm{C}_{3}, \mathrm{Cr}_{2} \mathrm{O}_{3}, \mathrm{Cr}_{3} \mathrm{C}_{2}\right)$, and high $\left(\mathrm{Cr}_{2} \mathrm{O}_{3}\right)$ oxygen content ${ }^{51}$. At the onset of oxidation process, at low oxygen content, $\mathrm{Cr}_{7} \mathrm{C}_{3}, \mathrm{Cr}$, and $\mathrm{Cr}_{3} \mathrm{C}_{2}$ forms first, which is followed by the reaction of oxygen with $\mathrm{Cr}_{2} \mathrm{AlC}$ that gradually transforms from $\mathrm{Cr}_{7} \mathrm{C}_{3}$ to $\mathrm{Cr}_{3} \mathrm{C}_{2}$ and disappears at oxygen higher exposure, i.e., the $\mathrm{Cr}_{2} \mathrm{AIC}$ MAX phase eventually disintegrates into $\mathrm{Al}_{2} \mathrm{O}_{3}$ and $\mathrm{Cr}_{2} \mathrm{O}_{3}$, and gaseous $\mathrm{CO}_{2}$.
The predicted oxidation reaction chain for $\mathrm{Cr}_{2} \mathrm{AIC}$ at $1200 \mathrm{~K}$ is shown in Table 3 (also see Supplementary Table 8 ) The reaction table shows thermodynamically stable oxidation reaction products at varying oxygen mole fractions. The molar-oxygen content is varied to show its effect on reaction products, which represents the exposure time of the alloy to static air in experimental conditions. The reaction products of the chemical process during the selective oxidation of $\mathrm{Al}$ or $\mathrm{Cr}$ in $\mathrm{Cr}_{2} \mathrm{AlC}$ for low/intermediate oxygen exposure can be written as:

$\mathrm{Cr}_{2} \mathrm{AlC}+\mathrm{O}_{2} \rightarrow \mathrm{Cr}_{7} \mathrm{C}_{3}+\mathrm{Al}_{2} \mathrm{O}_{3}+\mathrm{C}$,

i.e., the $\mathrm{Cr}_{2} \mathrm{AlC}$ oxidation shows $\mathrm{Al}_{2} \mathrm{O}_{3}$ and $\mathrm{Cr}_{7} \mathrm{C}_{3}$ as the reaction product. The $\mathrm{Cr}_{7} \mathrm{C}_{3}$ forms just below the surface layer of $\mathrm{Al}_{2} \mathrm{O}_{3}$ due to Al consumption ${ }^{28}$.

For longer exposure time to static air, $\mathrm{Cr}_{7} \mathrm{C}_{3}$ further decomposes and allows the formation of $\mathrm{Cr}_{2} \mathrm{O}_{3}$ while excess $\mathrm{C}$ diffuses through $\mathrm{Cr}_{2} \mathrm{O}_{3}$ and oxidizes into $\mathrm{CO}_{2}-$

$$
\mathrm{Cr}_{2} \mathrm{AlC}+\mathrm{O}_{2} \rightarrow \mathrm{Al}_{2} \mathrm{O}_{3}+\mathrm{Cr}_{2} \mathrm{O}_{3}+\mathrm{CO}_{2} \text {. }
$$

Here, the diffusion of $\mathrm{Cr}$ to the surface and $\mathrm{O}$ into the MAX phase or oxidation product during the oxidation process works as the rate-limiting condition. The $\mathrm{C}$ and $\mathrm{Al}_{2} \mathrm{O}_{3}$ were formed at intermediate/higher mole oxygen in region III/IV, see Table 3, while no $\mathrm{Cr}$ was found. Also, the presence of $\mathrm{Cr}_{2} \mathrm{O}_{3}$ along with $\mathrm{Al}_{2} \mathrm{O}_{3}{ }^{52}$ agrees with our prediction, which is known to help the formation of $\mathrm{Al}_{2} \mathrm{O}_{3}{ }^{53}$.

Importantly, $\mathrm{Al}_{2} \mathrm{O}_{3}$ starts appearing from intermediate (region II-III) to higher (IV-V) at all temperatures due to the high chemical activity of $\mathrm{Al}$ compared to $\mathrm{Cr} / \mathrm{C}$, see Fig. 10. The strong ionic/ covalent bonding of $\mathrm{Cr}$ with $\mathrm{C}$ in $\mathrm{Cr}_{2} \mathrm{AlC}^{54,55}$ decreases the oxygen 


\begin{tabular}{|c|c|c|c|}
\hline \multirow[t]{3}{*}{ Stages } & \multirow[t]{3}{*}{ Mole-oxygen } & \multicolumn{2}{|c|}{$\begin{array}{l}\text { Reaction products and phases-fractions } \\
{\left[\mathrm{Ti}_{2} \mathrm{AlC}+\mathrm{O}_{2}\right]}\end{array}$} \\
\hline & & \multicolumn{2}{|l|}{$1200 \mathrm{~K}$} \\
\hline & & Phase & Phase-fraction \\
\hline \multirow[t]{2}{*}{ I. } & 0.6 & $\begin{array}{l}\mathrm{Cr}_{2} \mathrm{AlC}+\mathrm{Cr}_{7} \mathrm{C}_{3}+\mathrm{Cr}+ \\
\mathrm{Al}_{4} \mathrm{CO}_{4}\end{array}$ & $(0.47,0.18,0.18,0.18)$ \\
\hline & 1 & $\begin{array}{l}\mathrm{Cr}_{2} \mathrm{AlC}+\mathrm{Cr}_{7} \mathrm{C}_{3}+\mathrm{Cr}+ \\
\mathrm{Al}_{4} \mathrm{CO}_{4}\end{array}$ & $(0.00,0.33,0.33,0.33)$ \\
\hline II. & 1.75 & $\begin{array}{l}\mathrm{Cr}_{7} \mathrm{C}_{3}+\mathrm{Al}_{2} \mathrm{O}_{3}+\mathrm{Cr}_{2} \mathrm{O}_{3}+ \\
\mathrm{Cr}_{3} \mathrm{C}_{2}\end{array}$ & $(0.13,0.49,0.29,0.08)$ \\
\hline \multirow[t]{2}{*}{ III. } & 2.75 & \multirow{2}{*}{$\underset{\mathrm{C}}{\mathrm{Al}_{2} \mathrm{O}_{3}+\mathrm{Cr}_{2} \mathrm{O}_{3}+\mathrm{Cr}_{3} \mathrm{C}_{2}+}$} & $(0.32,0.27,0.25,0.15)$ \\
\hline & 4 & & $(0.23,0.38,0.05,0.35)$ \\
\hline \multirow[t]{2}{*}{ IV. } & 4.75 & \multirow[t]{2}{*}{$\mathrm{Al}_{2} \mathrm{O}_{3}+\mathrm{Cr}_{2} \mathrm{O}_{3}+\mathrm{C}+\mathrm{CO}_{2}$} & $(0.20,0.40,0.35,0.05)$ \\
\hline & 6.3 & & $(0.20,0.40,0.04,0.36)$ \\
\hline \multirow[t]{2}{*}{ V. } & 7 & \multirow[t]{3}{*}{$\mathrm{Al}_{2} \mathrm{O}_{3}+\mathrm{Cr}_{2} \mathrm{O}_{3}+\mathrm{CO}_{2}+\mathrm{O}$} & $(0.17,0.33,0.33,0.17)$ \\
\hline & 9 & & $(0.09,0.20,0.50,0.19)$ \\
\hline I. & 11 & & $(0.07,0.14,0.64,0.14)$ \\
\hline
\end{tabular}

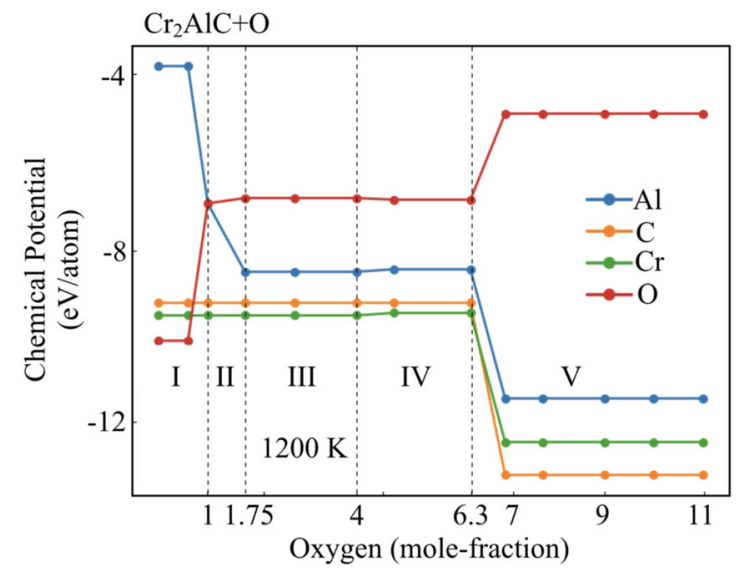

Fig. 10 Chemical activity of elements during oxidation process. Oxidation reaction chain showing change in chemical potential of $\mathrm{Cr}_{2} \mathrm{AlC}$ as a function of changing molar percent oxygen at $1200 \mathrm{~K}$. On oxidation, the partial chemical potentials of $\mathrm{Cr} / \mathrm{Al} / \mathrm{C}$ reduce while the chemical potential of invading $\mathrm{O}_{2}$ increases (see Supplementary Fig. 3).

affinity of $\mathrm{Cr}$. The presence of $\mathrm{Al}_{2} \mathrm{O}_{3}$ can also be understood in terms of weaker bonding of $\mathrm{Cr}$ with $\mathrm{Al}$, where weak metallic bonding between $\mathrm{Cr}^{-\mathrm{Al}^{36}}$ can contribute to the increased $\mathrm{Al}$ diffusivity at higher temperature and oxygen content. This makes the reaction $\mathrm{Al}$ with $\mathrm{O}$ more favorable, which leads to the formation of $\mathrm{Al}_{2} \mathrm{O}_{3}$ surface layer. The formation of the $\mathrm{Al}_{2} \mathrm{O}_{3}$ layer at the surface will slow down the oxidation of $\mathrm{Cr}_{2} \mathrm{AlC}$, i.e., protects the MAX phase.

In spite of good oxidation behavior, Cr2AIC also has some drawbacks, e.g., the thermal-expansion coefficients of three major phases $\mathrm{Cr}_{2} \mathrm{AlC}_{1} \mathrm{Al}_{2} \mathrm{O}_{3}$, and $\mathrm{Cr}_{7} \mathrm{C}_{3}$ were $13.3 \times 10^{-6}$ (per K) ${ }^{48}, 10.6 \times$ $10^{-6}$ (per $\left.\mathrm{K}\right)^{56}$, and $(7.2 \times 8.6) \times 10^{-6}$ (per $\mathrm{K}$ ), respectively. Large difference in thermal-expansion coefficient of $\mathrm{Al}_{2} \mathrm{O}_{3}$ and $\mathrm{Cr}_{7} \mathrm{C}_{3}$ with respect to $\mathrm{Cr}_{2} \mathrm{AlC}$ that forms immediately below the $\mathrm{Al}_{2} \mathrm{O}_{3}$ surface layer can generate excessive thermal and compressive stress in $\mathrm{Al}_{2} \mathrm{O}_{3}$, which may lead to spalling and cracking.

The chemical activity of constituent elements in $\mathrm{Cr}_{2} \mathrm{AlC}+\mathrm{O}_{2}$ oxidation process at $1200 \mathrm{~K}$ is shown in Fig. 10. Four zones in chemical potentials plot can be classified as (region I-II) quick change in $\mathrm{Al} / \mathrm{O}_{2}$ activity for $\mathrm{Al} / \mathrm{O}$; (region III-IV) slow activity region, and (region $\mathrm{V}$ ) sharply varying region at higher increasing oxygen content. The sharp change in chemical potential in region $\mathrm{V}$ occurs as $\mathrm{C}$ oxidizes into gaseous $\mathrm{CO}_{2}$. The occurrence of $\mathrm{C}$ and $\mathrm{CO}_{2}$ at higher temperature suggests loss of carbon. The calculated trend in chemical potential in Fig. 10 suggests increased oxygen activity at higher oxygen content.

At higher oxygen content in region $\mathrm{V}$, the $\mathrm{Cr}_{2} \mathrm{AIC}$ MAX phase decomposes into stable $\mathrm{Cr}_{2} \mathrm{O}_{3}$, and $\mathrm{Al}_{2} \mathrm{O}_{3}$ phases, which lowers the chemical potential $\mathrm{Cr} / \mathrm{Al} / \mathrm{C}$ compared to $\mathrm{O}_{2}$. This suggests an increased outward diffusion of $\mathrm{Al}$ and $\mathrm{Cr}$ and leads to formation protective oxide layers. The lowered chemical potential with increasing oxygen content and weak $\mathrm{Cr}$-Al bonding ${ }^{36,46}$ keep the constant supply of $\mathrm{Al}$ at all temperatures for the Al-O reaction. The chemical activity of $\mathrm{Al}$, as shown in Fig. 10, is slightly higher than that of $\mathrm{Cr}$ and $\mathrm{C}$, suggesting that the formation of $\mathrm{Al}_{2} \mathrm{O}_{3}$ is relatively faster process. Therefore, protective $\mathrm{Al}_{2} \mathrm{O}_{3}$ layers are formed quickly on $\mathrm{Cr}_{2} \mathrm{AlC}$ substrate and stops further degrading due to oxygen attack. $\mathrm{Al}_{2} \mathrm{O}_{3}$ formation is also preferred because of lower vapor pressure of $\mathrm{Al}$ with respect to $\mathrm{O}$ when compared to $\mathrm{Cr}$ with respect to $\mathrm{O}$. At low oxygen content (region I-III), the oxidized surface of the film is a mixture of the $\mathrm{Al}_{2} \mathrm{O}_{3}$ and $\mathrm{Cr}_{2} \mathrm{O}_{3}$ depending on exposure time or oxygen content to $\mathrm{O}_{2}$.

The thermodynamic stability, outstanding mechanical behavior, and superior oxidation resistance make MAX phases a promising material for high-temperature applications, such as, nuclear, aerospace, and/or turbines. We present a ML-based highthroughput scheme to assess oxidation behavior of crystalline MAX phases. The workflow combines the Bartel (SISSO) model (based on SISSO approach) with grand-canonical linear programming (GCLP) method into a single framework. The scheme predicts temperature-dependent $\Delta G_{\text {form }}$, possible reaction products, and chemical activity of alloying elements. The validation test performed on binary oxides, e.g., Ti-O and Al-O, which shows good agreement with existing experiments. We performed phase stability of analysis of 30 MAX phases of 211 chemistry. To exemplify our approach, we choose $\mathrm{Ti}_{2} \mathrm{AIC}$ MAX phase due to its superior oxidation resistance. The theoretically predicted reaction path with increasing oxygen content at high operating temperatures confirmed by our breakaway oxidation experiments. We believe that the prediction of improved high-temperature behavior due to ever-growing demand of new structural materials for high-temperature application makes our scheme useful, and timely. The application of the proposed method for $\mathrm{Cr}_{2} \mathrm{AlC}$ establishes the generality of the scheme, which will further guide experimentalists in understanding the relative phase stability of any inorganic alloy system and its reaction path during oxidation. We successfully explain the metastable $\mathrm{Ti}_{2} \mathrm{SiC}$ MAX phase, which further establishes the strength of our framework.

Our proposed high-throughput scheme enables the quick assessment of the oxidation stability of a large alloy space and reduce the time and cost for alloy selection for design--this approach is many orders of magnitude faster than when using conventional DFT-only approaches and is applicable even when no suitable CALPHAD databases are available. This will help to filter specific elements during alloy design to minimize material degradation due to formation unstable oxides. We also note some minor disagreement between prediction and the experiment. The most plausible reason for disagreement may arise from not including all possible non-stoichiometric compounds, ternaryoxides/oxycarbides, and/or contributions from kinetics, i.e., sluggish diffusion and/or significant barriers to nucleation and growth of phases. However, keeping the complexity of the 


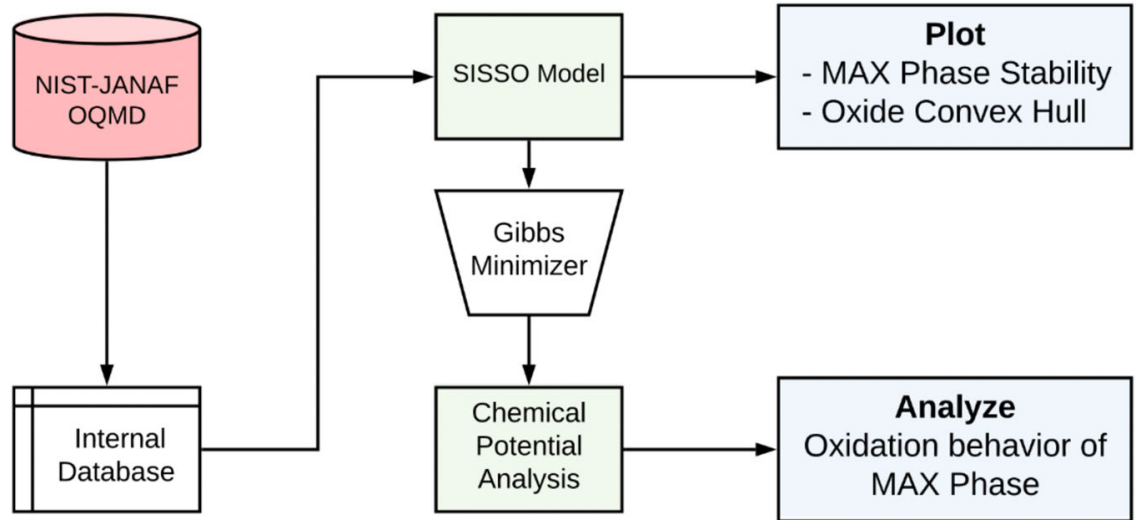

Fig. 11 Schematic representation of the workflow. The SISSO and GCLP-based machine-learning workflow to predict oxide phase selection and stability of MAX phases.

problem in mind, the proposed scheme provides good quantitative agreement with experiments.

\section{METHODS}

High-throughput framework

We develop an in-house machine-learning-based high-throughput scheme (see schematic in Fig. 11), which is capable of predicting $\Delta G_{\text {form }}$ using $\mathrm{SISSO}^{21}$ and phase-prediction, as well as chemical activity of constituent elements using GCLP model ${ }^{23,24}$ in inorganic stoichiometric phases. The SISSO model ${ }^{21}$ uses NIST-JANAF ${ }^{26,27}$, and OMD (DFT) ${ }^{27}$ database to predict $\Delta G_{\text {form }}$ across the temperature range.

\section{NIST-JANAF and OQMD (DFT) database}

The experimental formation energy $\left(E_{\mathrm{form}}\right)$ data for transition metal oxides was extracted from the NIST-JANAF thermochemical database ${ }^{25,26}$. We also calculated $E_{\text {form }}$ from DFT using structure files from DFT-based Open Quantum Materials Database (OQMD) ${ }^{27}$ for each oxide phase.

\section{Sure independence screening and sparsifying operator}

Much of the research into developing models for predicting MAX phase stability has utilized computationally intensive methods ${ }^{57,58}$, such DFT calculations carried out using the Vienna Ab initio Simulation Package $(\text { VASP })^{59,60}$. Expensive DFT estimates of the entropic $(\Delta S)$ contributions in the calculation of $\Delta G_{\text {form }}$ limits their use in accelerated material design ${ }^{61}$. Fortunately, it has been demonstrated that DFT calculations augmented with machine learning and experimentally acquired information provides the means for predicting material properties quickly and accurately ${ }^{21}$. The SISSO framework, for example, is an emerging machine-learning algorithm capable of arriving at accurate predictions of material properties through models that employ physically meaningful features ${ }^{17-19}$. Here, we utilize the descriptor-based model from Bartel for the finite-temperature Gibbs energy of an arbitrary inorganic stoichiometric phase ${ }^{21}$ :

$$
\begin{aligned}
& \mathrm{G}^{\mathrm{SISSO}}(\mathrm{eV} / \text { atom })=\left(-2.48 \cdot 10^{-4} \cdot \ln (\mathrm{V})-8.94 \cdot 10^{-5} \cdot \mathrm{mV}^{-1}\right) \\
& \mathrm{T}+0.181 \cdot \ln (\mathrm{T})-0.882
\end{aligned}
$$

for the fast assessment of $\Delta G_{\text {form }}=\Delta H_{\text {form }}+\Delta G^{\text {SISSO }}(T)-\sum_{\mathrm{i}} x_{\mathrm{i}} \Delta G_{\mathrm{i}}(T)$, and validate the approach for binary oxides (Ti-O and $\mathrm{Al}-\mathrm{O}$ ) with respect to temperature and oxygen concentration. We test the predicted $\Delta G_{\text {form }}$ of transition metal oxides in $300-2000 \mathrm{~K}$ temperature range ${ }^{18,19}$. The predicted $\Delta G_{\text {form }}$ were compared to experimental data from the NISTJANAF thermochemical tables to determine the model accuracy across a wide temperature range. Additionally, a convex hull was generated for the titanium-oxygen chemical system using the model predictions as a validation test. The SISSO model was then used to assess the thermodynamic stability of $M_{2} A C M A X$ phases to identify the effect of transition metal-elements (M), where $\mathrm{M}=\mathrm{Sc}, \mathrm{Y}, \mathrm{Ti}, \mathrm{Zr}, \mathrm{Hf}, \mathrm{V}, \mathrm{Nb}, \mathrm{Ta}, \mathrm{Cr}, \mathrm{Mo}, \mathrm{Mn}, \mathrm{Fe}, \mathrm{Co}$, $\mathrm{Ni}$, and $\mathrm{Cu}$ ) in MAX phases with $\mathrm{A}=\mathrm{Al}$, and $\mathrm{Si}$.

\section{Grand canonical linear programming}

The linear nature of the Gibbs energy minimization problem allows the use of linear programming-based algorithms to identify the equilibrium configuration of chemical systems under arbitrary thermodynamic conditions. The GCLP method is one such approach ${ }^{24,25}$, and we use it in this study to predict thermodynamically favorable phases from $\mathrm{Ti}_{2} \mathrm{AIC}+$ $\mathrm{O}_{2}$ reactions by breaking down the system into a series of linear equations for the different chemical reactions that can take place at given temperature and given oxygen content. The GCLP minimizes the Gibbs energy of the mixture of the elements at a given $\mathrm{Ti}, \mathrm{M}, \mathrm{C}$, and $\mathrm{O}$ composition (for example):

$$
\Delta G=\sum_{\text {phase }} f_{\text {phase }} \cdot \Delta G_{\text {phase }}
$$

where, $\Delta G_{\text {phase }}$ is the Gibbs free energy of each competing phase "phase" and $f_{\text {phase }}$ is the phase-fraction. We minimize $\Delta G$ to determine the molar fraction of each phase. The predicted phase stability is used to estimate chemical potential of each element against given oxygen molar composition. These results are then compared with experimental data to assess the accuracy of the predictions. We note that the oxidation reaction at the interface of MAX phase is a phase selection process and the most favorable product phases tend to be those possessing the lowest combined energy relative to the reactants, i.e., this yields highest possible oxidation reactivity. The reliability of GCLP approach depends on the accuracy of free energy database. We use free-energy database constructed from NIST-JANAF (experiments) ${ }^{25,26}, \mathrm{OQMD}^{27}$, and DFT ${ }^{62,63}$.

\section{Vacancy calculation}

Our experiments indicate the importance of Al deficiency (vacancy formation) in the selective oxidation and oxidation stability of $\mathrm{Ti}_{2} \mathrm{AlC}$ MAX phase (see supplemental Supplementary Fig. 6). The input structures of $\mathrm{Ti}_{2}\left(\mathrm{Al}_{1-x} \mathrm{Va}_{x}\right) \mathrm{C}$ for $x$ (in at.\%) $=3.125, x=6.25$, and $x=9.375$ for the DFT calculations were modeled using 128-atom special quasi-random structures ${ }^{64,65}$. The stability of Al-depleted $\mathrm{Ti}_{2} \mathrm{AIC}_{1} \mathrm{Ti}_{2}\left(\mathrm{Al}_{1-x} \mathrm{Va}_{x}\right) \mathrm{C}$, relative to the competing intermetallic phases was investigated using GCLP. DFT$\operatorname{VASP}^{59,60}$ was used for structural minimization, total energy and formation enthalpy calculation of vacancy structures. Forces and total energies are converged to $-0.001 \mathrm{eV}$ per $\AA$ and $10^{-5} \mathrm{eV}$ per cell, respectively. Both for relaxation and energy calculation, we used Perdew, Burke and Ernzerhof (PBE) generalized gradient approximation with a planewave cut-off energy of $533 \mathrm{eV}^{66}$. The geometry-optimization and charge self-consistency of each MAX phase is done using gamma-centered Monkhorst-Pack ${ }^{67} \mathrm{k}$-mesh a $3 \times 3 \times 3$ and $5 \times 5 \times 5$, respectively. The formation enthalpies of with and without vacancy MAX phases are calculated using the information of element energies.

\section{Material preparation}

$\mathrm{Ti}, \mathrm{Al}$, and $\mathrm{TiC}$ powders are mixed in 1.05:1.05:0.95 atomic ratio in a glass jar. The (Ti, Al, TiC) powder is ball milled for mixed for $24 \mathrm{~h}$. The $\mathrm{ZrO}_{2}$ balls are used to grind the mixture to make the powder finer at the rotation speed of $300 \mathrm{rmp}$. The powder mixture is poured into an alumina crucible (AdValue Technology, US) and heated up to $1400^{\circ} \mathrm{C}$ at a $10^{\circ} \mathrm{C} / \mathrm{min}$ heating 
rate in $\mathrm{Ar}$ atmosphere for $4 \mathrm{~h}$ in a tube furnace (MTI Corporation, CA). The low-density $\mathrm{Ti}_{2} \mathrm{AlC}$ is drilled and meshed into powder with particle size smaller than $90 \mu \mathrm{m}$. The fine $\mathrm{Ti}_{2} \mathrm{AlC}$ powder is poured into a graphite die $(20 \mathrm{~mm}$ in diameter) loaded with $100 \mathrm{MPa}$ pressure heated by Pulsed Electric Current Sintering (PECS, GT Advanced Technologies, CA) to $1400^{\circ} \mathrm{C}$ in the $\mathrm{Ar}$ atmosphere and densified for $15 \mathrm{~min}$. The full-dense $\mathrm{Ti}_{2} \mathrm{AlC}$ cylinders are cut into discs of $19.6 \mathrm{~mm}$ diameter and $2 \mathrm{~mm}$ thickness using wire electrical discharge machining (EDM). The EDM layers are then removed followed by mechanical polishing to $0.1 \mu \mathrm{m}$ prior and diamond paste finish before joining the pieces.

\section{Fabrication of wedge-shaped samples and oxidation testing}

An Al coupon is placed on a hot plate (Thermo Scientific) and heated up to $80^{\circ} \mathrm{C}$. Then, the crystalbond (Ted Pella) is used to join the $\mathrm{Ti}_{2} \mathrm{AlC}$ discs with Al coupon. After cooling down, the bonded couples are carefully polished on the $\mathrm{Ti}_{2} \mathrm{AlC}$ side to a wedge shape with a $3.5 \pm 0.20$ taper and the thickness from 30 to $500 \mu \mathrm{m}$. Oxidation tests are carried out in a box furnace (Carbolite, UK). The couples are placed in acetone (Macron Fine Chemicals) to debond and the wedge-shaped $\mathrm{Ti}_{2} \mathrm{AlC}$ samples are kept on the alumina crucibles in the hot chamber and oxidized in static air.

\section{Characterization}

The cross sections of the oxidized wedge-shaped $\mathrm{Ti}_{2} \mathrm{AlC}$ samples are mechanically polished to $0.1 \mu \mathrm{m}$ diamond paste finish. Scanning Electron Microscopies (FE-SEM, Quanta 600 FEG, FEl, Oregon, USA) equipped with Energy Dispersive Spectroscopy (EDS) are used to analyze the microstructure and composition of phases along the wedge. The average critical thickness is measured from SEM images. Electron microprobe analysis (EPMA) is used for a quantitative phase evaluation in the breakaway oxidation region in $\mathrm{Ti}_{2} \mathrm{AlC}$. We use electron backscattered diffraction (EBSD) in the same region to identify exact phases. The sample is polished using a $0.05 \mu \mathrm{m}$ colloidal silica solution prior to the EBSD characterization. A Zeiss Ultra Plus FEGSEM equipped with an Oxford Instrument Aztec EBSD system and a Nordlys nano EBSD detector was used for the characterization.

\section{DATA AVAILABILITY}

The authors declare that the data supporting the plots and findings of this study are available within the paper/supplement, and also with the corresponding authors upon reasonable request.

\section{CODE AVAILABILITY}

The authors declare that the code supporting this study are available with the corresponding authors upon reasonable request.

Received: 11 May 2020; Accepted: 10 November 2020; Published online: 04 January 2021

\section{REFERENCES}

1. Barsoum, M. W. MAX Phases: Properties of Machinable Ternary Carbides and Nitrides. (Wiley, 2013).

2. Dahlqvist, M., Alling, B. \& Rosén, J. Stability trends of MAX phases from first principles. Phys. Rev. B 81, 220102 (2010).

3. Sokol, M., Natu, V., Kota, S. \& Barsoum, M. W. On the chemical diversity of the MAX phases. Trend. Chem. 1, P210-223 (2019).

4. Radovic, M. \& Barsoum, M. W. MAX phases: Bridging the gap between metals and ceramics. Am. Ceram. Soc. Bull. 92, 20-27 (2013).

5. Barsoum, M. W. \& Radovic, M. Elastic and mechanical properties of the MAX phases. Annu. Rev. Mater. Res. 412011, 195-227 (2011).

6. Radovic, M. et al. On the elastic properties and mechanical damping of $\mathrm{Ti}_{3} \mathrm{SiC}_{2}$ $\mathrm{Ti}_{3} \mathrm{GeC}_{2}, \mathrm{Ti}_{3} \mathrm{Si}_{0.5} \mathrm{Al}_{0.5} \mathrm{C}_{2}$ and $\mathrm{Ti}_{2} \mathrm{AlC}$ in the $300-1573 \mathrm{~K}$ temperature range. Acta Mater. 54, 2757-2767 (2006).

7. Tallman, D. J., Anasori, B. \& Barsoum, M. W. A critical review of the oxidation of Ti2AIC, Ti3AIC2 and Cr2AIC in air. Mater. Res. Lett. 1, 115-125 (2013).

8. Barsoum, M. W., Ho-Duc, L. H., Radovic, M. \& El-Raghy, T. Long time oxidation study of $\mathrm{Ti}_{3} \mathrm{SiC}_{2}, \mathrm{Ti}_{3} \mathrm{SiC}_{2} / \mathrm{SiC}$, and $\mathrm{Ti}_{3} \mathrm{SiC}_{2} / \mathrm{TiC}$ composites in air. J. Electrochem. Soc. 150, B166-B175 (2003).
9. Smialek, J. L. Unusual oxidative limitations for Al-MAX phases. (NASA/TM-2017219444, Cleveland, OH, 2017).

10. Prescott, R. \& Graham, M. J. The formation of aluminum oxide scales on hightemperature alloys. Oxid. Met. 38, 233-254 (1992).

11. Wang, J. \& Zhou, Y. Recent progress in theoretical prediction, preparation, and characterization of layered ternary transition-metal carbides. Annu. Rev. Mater. Res. 39, 415-443 (2009).

12. Cui, B. \& Lee, W. E. High-temperature oxidation behaviour of MAX phase ceramics. Refractories Worldforum 5, 105-112 (2013).

13. Lee, W. E., Zhang, S. \& Karakus, M. Refractories: controlled microstructure composites for extreme environments. J. Mater. Sci. 39, 6675-6685 (2004).

14. Cui, B., Jayaseelan, D. D. \& Lee, W. E. Microstructural evolution during hightemperature oxidation of $\mathrm{Ti}_{2} \mathrm{AlC}$ ceramics. Acta Mater. 59, 4116-4125 (2011).

15. Cui, B., Jayaseelan, D. D. \& Lee, W. E. TEM study of the early stages of Ti2AIC oxidation at $900^{\circ} \mathrm{C}$. Scr. Mater. 67, 830-833 (2012).

16. Tolpygo, V. K., Dryden, J. R. \& Clarke, D. R. Determination of the growth stress and strain in $\mathrm{a}-\mathrm{Al}_{2} \mathrm{O}_{3}$ scales during the oxidation of $\mathrm{Fe}-22 \mathrm{Cr}-4.8 \mathrm{Al}-0.3 \mathrm{Y}$ alloy. Acta Mater. 46, 927-937 (1998)

17. Tolpygo, V. K. \& Clarke, D. R. Competition between stress generation and relaxation during oxidation of an Fe-Cr-Al-Y Alloy. Oxid. Met. 49, 187-212 (1998).

18. Huntz, A. M. Stresses in $\mathrm{NiO}, \mathrm{Cr}_{2} \mathrm{O}_{3}$ and $\mathrm{Al}_{2} \mathrm{O}_{3}$ oxide scales. Mat. Sci. Eng. A 201, 211-228 (1995).

19. Duong, T. C., Talapatra, A., Son, W., Radovic, M. \& Arroyave, R. On the stochastic phase stability of $\mathrm{Ti}_{2} \mathrm{AlC}-\mathrm{Cr}_{2} \mathrm{AlC}$. Sci. Rep. 7, 5138 (2017).

20. Ghiringhelli, L. M., Vybiral, J., Levchenko, S. V., Draxl, C. \& Scheffler, M. Big data of materials science: critical role of the descriptor. Phys. Rev. Lett. 114, 105503 (2015).

21. Bartel, C. J. et al. Physical descriptor for the Gibbs energy of inorganic crystalline solids and temperature-dependent materials chemistry. Nat. Commun. 9, 4168 (2018).

22. Ouyang, R., Curtarolo, S., Ahmetcik, E., Scheffler, M. \& Ghiringhelli, L. M. SISSO: A compressed-sensing method for identifying the best low-dimensional descriptor in an immensity of offered candidates. Phys. Rev. Mater. 2, 083802 (2018).

23. Akbarzadeh, A. R., Ozolins, V. \& Wolverton, C. First-principles determination of multicomponent hydride phase diagrams: application to the Li-Mg-N-H system. Adv. Mater. 19, 3233-3239 (2007).

24. Kirklin, S., Meredig, B. \& Wolverton, C. High-throughput computational screening of new li-ion battery anode materials. Adv. Energy Mater. 3, 252-262 (2013).

25. Chase, M. W. et al. JANAF Thermochemical Tables, 3rd edn. (ed. Lide, Jr., D. R.). (American Institute of Physics, New York, 1986).

26. Chase, M. W. Jr. et al. JANAF thermochemcial table 3d edition. J. Phys. Chem. Ref. Data 14, 2 (1985).

27. Saal, J. E., Kirklin, S., Aykol, M., Meredig, B. \& Wolverton, C. Materials design and discovery with high-throughput density functional theory: the open quantum materials database (OQMD). JOM 65, 1501-1509 (2013).

28. Wang, X. H. \& Zhou, Y. C. High-temperature oxidation behavior of $\mathrm{Ti}_{2} \mathrm{AlC}$ in air. Oxid. Met. 59, 303-320 (2003).

29. Basu, S., Obando, N., Gowdy, A., Karaman, I. \& Radovic, M. Long-term oxidation of $\mathrm{Ti}_{2} \mathrm{AIC}$ in air and water vapor at $1000-1300^{\circ} \mathrm{C}$ temperature range. J. Electrochem. Soc. 159, C90-C96 (2012).

30. Oses, C. et al. AFLOW-CHULL: cloud-oriented platform for autonomous phase stability analysis. J. Chem. Inf. Model. 58, 2477-2490 (2018).

31. Eklund, P., Beckers, M., Jansson, U., Hogberg, H. \& Hultman, L. The $M_{n+1} A X_{n}$ phases: materials science and thin-film processing. Thin Solid Films 518, 1851-1878 (2018).

32. Hug, G. Electronic structures of and composition gaps among the ternary carbides $\mathrm{Ti}_{2}$ MC. Phys. Rev. B 74, 184113 (2006)

33. Thore, A., Dahlqvist, M., Alling, B. \& Rosen, J. Temperature dependent phase stability of nanolaminated ternaries from first-principles calculations. Comp. Mater. Sci. 91, 251-257 (2014).

34. Palmquist, J.-P. et al. $M_{n+1} A X_{n}$ phases in the Ti-Si-C system studied by thin-film synthesis and ab initio calculations. Phys. Rev. B 70, 165401 (2004).

35. Bandyopadhyay, D. The Ti-Si-C system (Titanium-Silicon-Carbon). J. Phase Equilib. Diffus. 25, 415-420 (2004).

36. Singh, P., Sauceda, D. \& Arroyave, R. The effect of chemical disorder on defect formation and migration in disordered MAX phases. Acta Mater. 184, 50-58 (2019).

37. Liao, T., Wang, J. \& Zhou, Y. Ab initio modeling of the formation and migration of monovacancies in $\mathrm{Ti}_{2} \mathrm{AlC}$. Scr. Mater. 59, 854-857 (2008).

38. $\mathrm{Du}, \mathrm{Y}$. et al. Anisotropic corrosion of $\mathrm{Ti}_{2} \mathrm{AlC}$ and $\mathrm{Ti}_{3} \mathrm{AlC}_{2}$ in supercritical water at $500^{\circ} \mathrm{C}$. Ceram. Int. 43, 7166-7171 (2017).

39. Rao, J. C. et al. TEM study of the initial oxide scales of $\mathrm{Ti}_{2} \mathrm{AlC}$. Acta Mater. 59, 5216-5223 (2011). 
40. Basu, S., Obando, N., Gowdy, A., Karaman, I. \& Radovic, M. Long-term oxidation of $\mathrm{Ti}_{2} \mathrm{AlC}$ in air and water vapor at 1000-1300 C temperature range. J. Electrochem. Soc. 159, C90-C96 (2011).

41. Pint, B. A., Walker, L. R. \& Wright, I. G. Characterization of the breakaway al content in alumina-forming alloys. Mater. High. Temp. 21, 175-185 (2004).

42. Quadakkers, W. J. \& Bennett, M. J. Oxidation induced lifetime limits of thin walled, iron based, alumina forming, oxide dispersion strengthened alloy components. Mater. Sci. Technol. 10, 126-131 (1994).

43. Quadakkers, W. J. \& Bongartz, K. The prediction of breakaway oxidation for alumina forming ODS alloys using oxidation diagrams. Mater. Corros. 45, 232-241 (1994).

44. Li, X., Zheng, L., Qian, Y., Xu, J. \& Li, M. Breakaway oxidation of $\mathrm{Ti}_{3} \mathrm{AlC}_{2}$ during long-term exposure in air at $1100{ }^{\circ} \mathrm{C}$. Corros. Sci. 104, 112-122 (2016).

45. Al-Badairy, H., Tatlock, G. J. \& Bennett, M. J. A comparison of breakaway oxidation in wedge-shaped and parallel sided coupons of FeCrAl alloys. Mater. High. Temp. 17, 101-107 (2000)

46. Lin, Z. J., Li, M. S., Wang, J. Y. \& Zhou, Y. C. High-temperature oxidation and hot corrosion of $\mathrm{Cr}_{2}$ AIC. Acta Mater. 55, 6182-6191 (2007).

47. Pint, B. A. Experimental observations in support of the dynamic-segregation theory to explain the reactive-element effect. Oxid. Met. 45, 1-37 (1996).

48. Tian, W. et al. Synthesis and thermal and electrical properties of bulk $\mathrm{Cr}_{2} \mathrm{AIC}$. Scr. Mater. 54, 841-846 (2006).

49. Zhou, Y. C. \& Sun, Z. M. Electronic structure and bonding properties of layeredmachinable $\mathrm{Ti}_{2} \mathrm{AlC}$ and $\mathrm{Ti}_{2} \mathrm{AlN}$ ceramics. Phys. Rev. B 61, 12570-12573 (2000).

50. Lin, Z., Zhou, Y., Li, M. \& Wang, J. In-situ hot pressing/solid-liquid reaction synthesis of bulk $\mathrm{Cr}_{2}$ AlC. Z. Metallkd. 96, 291-296 (2005).

51. Lee, D. B. \& Park, S. W. Oxidation of Cr2AIC between 900 and $1200^{\circ} \mathrm{C}$ in Air. Oxid. Met. 68, 211-222 (2007).

52. Besmann, T. M., Kulkarni, N. S. \& Spear, K. E. Thermochemical analysis and modeling of the $\mathrm{Al}_{2} \mathrm{O}_{3}-\mathrm{Cr}_{2} \mathrm{O}_{3}, \mathrm{Cr}_{2} \mathrm{O}_{3}-\mathrm{SiO}_{2}$, and $\mathrm{Al}_{2} \mathrm{O}_{3}-\mathrm{Cr}_{2} \mathrm{O}_{3}-\mathrm{SiO}_{2}$ systems relevant to refractories. J. Am. Ceram. Soc. 89, 638-644 (2006).

53. Birks, N., Meier, G. H. \& Pettit, F. S. in Introduction to the High-temperature of Metals, 2nd edn. (Cambridge University Press, England, 2006), p.124.

54. Lin, Z., Zhou, M., Zhou, Y., Li, M. \& Wang, J. Atomic scale characterization of layered ternary $\mathrm{Cr}_{2}$ AlC ceramic. J. Appl. Phys. 99, 076109 (2006).

55. Schneider, J. M., Sun, Z., Mertens, R., Uestel, F. \& Ahuja, R. Ab initio calculations and experimental determination of the structure of $\mathrm{Cr}_{2} \mathrm{AIC}$. Solid State Commun. 130, 445-449 (2004).

56. Berg, G., Friedrich, C., Broszeit, E. \& Berger, C. in Handbook of Ceramic Hard Materials (ed. Riedel, R.) (Wiley-VCH, Germany, 2000), p. 968.

57. Dahlqvist, M. \& Rosen, J. Predictive theoretical screening of phase stability for chemical order and disorder in quaternary 312 and 413 MAX phases. Nanoscale 12, 785-794 (2020).

58. Dahlqvist, M., Alling, B. \& Rosen, J. Stability trends of MAX phases from first principles. Phys. Rev. B 81, 220102R (2010).

59. Kresse, G. \& Hafner, J. Ab initio molecular dynamics for liquid metals. Phys. Rev. $B$ 47, 558-561 (1993).

60. Kresse, G. \& Joubert, D. From ultrasoft pseudopotentials to the projector augmented-wave method. Phys. Rev. B 59, 1758-1775 (1999).

61. Bai, Y., Srikanth, N., Chua, C. K. \& Zhou, K. Density functional theory study of Mn +1AXn phases: a review. Crit. Rev. Solid State Mater. Sci. 44, 56-107 (2019).

62. Sun, W. Q., Wolverton, C., Akbarzadeh, A. R. \& Ozolins, V. First-principles prediction of high-capacity, thermodynamically reversible hydrogen storage reactions based on $\left(\mathrm{NH}_{4}\right)_{2} \mathrm{~B}_{12} \mathrm{H}_{12}$. Phys. Rev. B 83, 3-6 (2011).

63. Aidhy, D., Zhang, Y. \& Wolverton, C. Prediction of a $\mathrm{Ca}\left(\mathrm{BH}_{4}\right)\left(\mathrm{NH}_{2}\right)$ quaternary hydrogen storage compound from first-principles calculations. Phys. Rev. B 84, 1-8 (2011).

64. Zunger, A., Wei, S. H., Ferreira, L. G. \& Bernard, J. E. Special quasirandom structures. Phys. Rev. Lett. 65, 353-356 (1990).
65. van de Walle, A. et al. Efficient stochastic generation of special quasirandom structures. Calphad 42, 13-18 (2013).

66. Perdew, J. P., Burke, K. \& Ernzerhof, M. Generalized gradient approximation made simple. Phys. Rev. Lett. 77, 3865-3868 (1996).

67. Monkhorst, H. J. \& Pack, J. D. Special points for Brillouin-zone integrations. Phys. Rev. B 13, 5188-5192 (1976).

\section{ACKNOWLEDGEMENTS}

We acknowledge support from National Science Foundation through grants no. (DMREF) CMMI-1729350. First-principles calculations were carried out at the Supercomputing Facility at Texas A\&M University. D.S. acknowledges the support of the National Science Foundation through grant no. NSF-DGE 1545403 (NRT-DESE: Data-Enabled Discovery and Design of Energy Materials).

\section{AUTHOR CONTRIBUTIONS}

R.A. proposed and supervised the entire project. D.S., A.R.F., and P.S. worked on the development and testing of the model. G.V. assisted at the final stage of mode development. P.S. and T.D. performed DFT simulations. D.S., P.S., and R.A. analyzed and discussed theory results. Y.C. prepared the wedge samples and performed oxidation experiments. M.R. supervised the experimental work. P.S. and R.A. prepared the final draft of the manuscript with input from all the authors.

\section{COMPETING INTERESTS}

The authors declare no competing interests.

\section{ADDITIONAL INFORMATION}

Supplementary information is available for this paper at https://doi.org/10.1038/ s41524-020-00464-7.

Correspondence and requests for materials should be addressed to P.S. or R.A.

Reprints and permission information is available at http://www.nature.com/ reprints

Publisher's note Springer Nature remains neutral with regard to jurisdictional claims in published maps and institutional affiliations.

(i) Open Access This article is licensed under a Creative Commons Attribution 4.0 International License, which permits use, sharing, adaptation, distribution and reproduction in any medium or format, as long as you give appropriate credit to the original author(s) and the source, provide a link to the Creative Commons license, and indicate if changes were made. The images or other third party material in this article are included in the article's Creative Commons license, unless indicated otherwise in a credit line to the material. If material is not included in the article's Creative Commons license and your intended use is not permitted by statutory regulation or exceeds the permitted use, you will need to obtain permission directly from the copyright holder. To view a copy of this license, visit http://creativecommons. org/licenses/by/4.0/.

(c) The Author(s) 2021 